\title{
¿MÁS ALLÁ DEL “CONSENSO DE WASHINGTON”? Un enfoque desde la política de algunas propuestas del Banco Mundial
}

\author{
Carlos M. Vilas*
}

Fecha de recepción: abril 2000

Fecha de aceptación y versión final: septiembre 2000

\begin{abstract}
Resumen: Durante la última década las recomendaciones de política del Banco Mundial han puesto énfasis en la reforma institucional y en un papel más activo del Estado en la promoción de las transformaciones económicas orientadas hacia el mercado. La atención prestada a estos temas contrasta con la trayectoria previa del organismo, preocupada sobre todo por la gestión de los grandes agregados macroeconómicos. La nueva temática es presentada como respondiendo a la conveniencia de it más allá del "Consenso de Washington" que influyó decisivamente en las reformas estructurales de la década de 1980 e inicios de la siguiente. Este artículo discute los alcances y limitaciones de la nueva propuesta desde una perspectiva política, poniendo el acento en las configuraciones de poder que enmarcan las recomendaciones del organismo. Se reconocen en éstas dos vertientes: una de carácter doctrinario, preocupada ante todo por completar el programa de reformas impulsado por el "Consenso", y otra, pragmática, que plantea la reformulación de algunas de sus premisas en aras de un efecto más equilibrado en términos económicos y sociales. Aunque difieren en el margen de acción que reconocen para el Estado, ambas variantes comparten un enfoque que da prioridad a los instrumentos de gestión respecto de los grandes objetivos del desarrollo, reduce la política a administración y soslaya la historicidad del Estado y de la construcción institucional.
\end{abstract}

Palabras Clave: Recomendaciones del Banco Mundial, reforma institucional, papel del Estado.

Abstract: Over the last decade, World Bank's political prescriptions have stressed on institutional reforms and on a more active role of the State in promoting market-oriented refoms. However, this organism has traditionally focused on macroeconomic aggregates. This new approach is rooted in 'Washington Consensus' and its a decisive impact on the structural reforms that took place over the nineties. This paper discusses, from a political perpective, achievements and limitations of this new approach. It emphasizes on the power configurations that frame this organism' prescriptions. These prescriptions have a double character. On one side, there is a doctrinary character: the fulfillment of the package of reforms. On the other side, there is a pragmatic character: the reformulation of some of its postulates in order to achieve, in economic and social terms, more balanced effects. Despite differences in the attributed State's scope of action, both perspectives emphasize on management tools to achieve the main goals for development, both of them reduce politics to administration, and both of them ignore historicity of States and of institutional frameworks.

Key words: World Bank's prescriptions, institutional reform, State's role.

\section{ANTECEDENTES}

La reestructuración económica de la última década y media respondió a una variedad de factores, de incidencia desigual en cada país y en distintos momentos; en conjunto, pusieron de relieve el agotamiento del Estado proveedor de bienes y servicios que con variantes populistas o desarrollistas existía en la mayor parte de países de la región. Ese Estado había otorgado expresión institucional a una particular correlación de fuerzas tanto entre grupos y clases dentro de cada país como entre éstos y los actores externos que progresivamente fueron adquiriendo fuerte gravitación interna. La crisis que detonó en la década de 1980 afectó a una modalidad dada de organización de la vida económica y de relación entre el Estado y el mercado, pero también al sistema de poder articulado a ella.

La intervención estatal fue considerada responsable principal del descalabro. Las teorías que toman como punto de partida el carácter por definición rentista del Estado tuvieron notable acogida, en contraste con su relativa marginalidad durante el medio siglo anterior: Sin embargo, el

Funcionario del Instituto Nacional de la Administración Pública y presidente del Instituto Argentino para el Desarrollo Económico. Las opiniones contenidas en el trabajo son personales y no involucran a dichos organismos. $\triangle$ cvilas@ciudad.com.ar 
redescubrimiento de las ventajas del mercado y de las perversidades del Estado no obedeció inicialmente tanto a una reconversión teórica como a la evidencia de la bancarrota fiscal; la reorientación fue encarada por necesidad más que por opción doctrinaria; las experiencias exitosas del thatcherismo y la reaganomics influyeron para transformar la necesidad en virtud, así como en la reorientación de las recomendaciones de los organismos financieros multilaterales. El acceso a la renegociación del endeudamiento externo y al financiamiento fresco fue condicionado a la ejecución de un conjunto de medidas de ajuste y reestructuración orientadas a desmontar los mecanismos intervencionistas y a ampliar los márgenes de libertad de los mercados. El paquete de reformas recibió fuerte impulso del conjunto de agencias financieras y de asistencia al desarrollo, gubernamentales y multilaterales, algunas de las cuales habían otorgado cierto aval al intervencionismo estatal hasta las vísperas del estallido de la crisis. No obstante, sería excesivo atribuir la adopción del enfoque neoliberal exclusivamente a las condiciones impuestas por esas agencias. Las premisas centrales del liberalismo económico formaban parte de las preferencias de los círculos doctrinarios vinculados a los actores económicos más ligados al comercio exterior y al sector financiero. Esta circunstancia también ayuda a explicar los desiguales alcances y solidez de las acciones inspiradas en la teoría.

Los esquemas intervencionistas y proteccionistas fueron desmontados o severamente reducidos, transfiriéndose activos y capacidades de decisión a los actores del mercado; se eliminaron los controles gubernamentales sobre la inversión, la fijación de precios, el crédito, las transacciones comerciales y financieras internas e internacionales, y se contrajo el gasto social. La consiguiente reasignación de recursos implicó cambios profundos en las relaciones de poder en la sociedad, que habrían de alcanzar expresión y refuerzo en la red institucional del Estado. Definido en términos elementales, el poder consiste en la capacidad de convencer u obligar a otros a hacer algo que no estaba en su intención hacer, o a abstenerse de algo que habrían querido hacer (Stoppino, 1982). Esto se logra movilizando una variedad de recursos, entre ellos los de carácter económico. Cuando se modifican la distribución y el uso de los recursos, cambian las relaciones entre individuos y grupos sociales, así como su jerarquización y capacidades de acción y de imposición de objetivos y metas.

La reestructuración generó ganadores y perdedores. El mayor peso reconocido al mercado en la asignación de recursos implicó mayor poder de los actores que retuvieron o alcanzaron posiciones de gravitación en él. La extraordinaria liquidez de la economía internacional, desarrollos importantes en la tecnología de las comunicaciones electrónicas, y la amplia desregulación, favorecieron el auge del capital financiero en detrimento de los sectores productivos. La desregulación y la mayor liquidez favorecieron importantes transferencias de activos que reforzaron la primacía de los segmentos más concentrados y centralizados del capital y la subordinación de las firmas pequeñas y medianas y las que tenían como referente principal el mercado doméstico. La mayor sensibilidad de las agencias gubernamentales a las sugerencias provenientes de esos segmentos del mercado dio aval institucional a grupos y actores particulares. Todo ello en el marco de una victoria del capital frente a la fuerza de trabajo, expresada en el retroceso de los mecanismos de negociación y de la eficacia de la organización, la movilización y la presión sindicales (Wolfe, 1990; Vilas, 1994a).

Estos cambios estimularon una mayor concentración de los ingresos y agravaron la desigual distribución de la carga del endeudamiento externo y de los costos y beneficios del ajuste. Más aún, provocaron una modificación radical de las grandes metas sociales que, con desigual compromiso y eficacia, habían definido hasta entonces el horizonte de la gestión publica. El discurso conservador que explicó la bancarrota fiscal por los excesos distributivos del Estado alcanzó una notable aceptación y sirvió para justificar los cambios impulsados desde el propio Estado. Los derechos y la organización laboral, cuestionados en el pasado en nombre de la defensa del mundo libre y de su confrontación a las variantes autóctonas del populismo o el comunismo, pasaron a ser estigmatizados en nombre de la eficiencia económica y el libre mercado. Los trabajadores y los gobiernos sensibles a sus demandas fueron responsabilizados de la crisis del capitalismo criollo.

El conjunto de recetas recibió el nombre de "Consenso de Washington", por la coincidencia de recomendaciones de política económica formuladas por los organismos propulsores de las reformas, todos ellos domiciliados en la capital de Estados Unidos. En un resumen elaborado por quien más contribuyó a la difusión de la denominación, el "Consenso" consistía de diez ingredientes de política económica: 1) disciplina fiscal; 2) priorización del gasto público en áreas de alto retorno económico; 3) reforma tributaria; 4) tasas positivas de interés fijadas por el mercado; 5) tipos de cambio competitivos y liberalización financiera; 6) políticas comerciales liberales; 7) apertura a la inversión extranjera; 8) privatizaciones; 9) desregulación amplia; 10) protección a la propiedad privada (Williamson, 1990, 1993). En opinión de sus voceros, el conjunto de estas premisas debería alcanzar el mismo nivel de aceptación que los derechos humanos o la lucha contra el racismo, en vez de estar sometidas a la controversia entre partidos. Los actores políticos responsables deberían dar prioridad a la promoción del "Consenso de Washington" y sacarlo del terreno contencioso del debate político'. En realidad, el "Consenso" resumió las recomendaciones de política de los programas de ajuste estructural que el Banco Mundial y el FMI estaban promoviendo con un estilo de "terapia de shock" -según la expresión atribuida a Jeffrey Sachs en su experiencia boliviana- desde inicios de la década de 1980 en varias decenas de países.

En América Latina la adopción de estas políticas por gobiernos surgidos de elecciones contribuyó a modificar el

1. Williamson recomendó la adopción del paquete a todo el espectro político, y en particular a los partidos de izquierda. Esto dejaría sub sistente un conjunto de grandes temas económicos, sobre todo el equili brio entre eficiencia y equidad, que debería ser determinado por el proceso político. Williamson postuló que la izquierda, entendida como la que da prioridad a la igualdad sobre la eficiencia, fortalecería su causa adoptan do la mainstream economics resumida en el Consenso de Washington (Williamson, 1993). 
significado asignado al "Consenso": éste no se referiría únicamente a un acuerdo entre organizaciones burocráticas impersonales, sino a la decisión de la ciudadanía de votar por los candidatos dispuestos a llevar el programa a la práctica. Varios de los ingredientes del paquete neoliberal habían sido parte integral de la política económica de regímenes autoritarios o francamente dictatoriales. Hasta la década de 1980 esta circunstancia abonó la identificación entre políticas neoliberales y autoritarismo político difundida en amplios sectores de la opinión pública y en ámbitos académicos ${ }^{2}$. En cambio, en los escenarios diseñados por la crisis y las "transiciones a la democracia" el programa neoliberal fue asumido por un buen número de los gobiernos surgidos de procesos electorales. La promoción de la economía de mercado y el levantamiento de los mecanismos de intervención estatal se convirtieron en el núcleo estratégico de las "nuevas democracias" latinoamericanas, que pasaron a recibir la denominación de democracias de mercado. La promoción de una determinada estrategia económica devino condición de reconocimiento y parámetro de evaluación de la calidad y la efectividad del régimen político y los arreglos institucionales ${ }^{3}$.

El papel del Estado debería reducirse a su nivel mínimo de provisión de bienes públicos, interpretados éstos en un sentido restrictivo. El desmantelamiento de los mecanismos de intervención requirió, sin embargo, una previa concentración de facultades decisorias en su aparato institucional, necesaria para impulsar la apertura y las desregulaciones, vencer las resistencias y modificar los equilibrios preexistentes. La retracción de la gestión pública en el terreno de la economía y de las relaciones sociales fue viabilizada por el fortalecimiento del Estado en cuanto expresión institucional del poder político y en definitiva coercitivo, en función de las nuevas metas y objetivos ${ }^{4}$. La manifestación más frecuente de esta ampliación de la soberanía estatal -es decir, de su capacidad para imponer decisiones con autoridad suprema respecto de la población de un territorio (Heller 1965) - fue la concentración de facultades en el ámbito del gobierno central y en particular del poder ejecutivo: delegación de facultades de competencia parlamentaria, normas legales de excepción o de emergencia, y similares. En momentos en que la literatura sobre consolidación de las transiciones democráticas abogaba por el acotamiento de las atribuciones políticas del poder ejecutivo (por ejemplo Stepan \& Skach 1993; Linz \& Valenzuela 1994), las exigencias de las democracias de mercado reforzaban la tradicional primacía presidencial respecto de los parlamentos y los tribunales (Weffort 1992; Vilas 1994b; O’Donnell 1995; Pereira Almao 1997).

\section{DEL "ESTADO MÍNIMO" AL "ESTADO EFECTIVO"}

El ajuste produjo resultados de signo variado. La región alcanzó una relativa estabilidad de precios -sobre todo en comparación con la década inmediatamente anterior-y retomó la senda del crecimiento. Se reanudaron los flujos de financiamiento externo y se dinamizó el comercio exterior.
El saneamiento de las cuentas públicas redujo los desequilibrios fiscales. Salvo excepciones -Chile, Argentina y en los últimos años República Dominicana-, las tasas de crecimiento del producto se ubican debajo de las que se registraron en las tres décadas posteriores a la segunda guerra mundial, y son muy sensibles a los vaivenes de la economía internacional; las tasas de la segunda mitad del decenio de 1990 son notoriamente más bajas que las de la primera mitad. La desregulación comercial y financiera alimentó mayores desequilibrios en las cuentas externas, financiados con un recurso creciente al endeudamiento. El retorno de la región a los mercados financieros internacionales se manifestó entre otros aspectos en un crecimiento muy rápido de la emisión de deuda pública. Los procesos de privatización generaron amplias transferencias de activos desde el Estado hacia inversores privados, con fuerte participación de no residentes. El modo en que esos procesos se desarrollaron favoreció la generación de altas tasas de rentabilidad en los sectores de bienes no transables, hacia los cuales se encaminó buena parte del nuevo endeudamiento externo, en detrimento de los sectores productores de exportables. Persiste la tradicional vulnerabilidad externa de la región, en la medida en que el nivel de actividad sigue dependiendo en medida importante de los precios de sus commodities y de la disponibilidad de financiamiento externo.

La reestructuración estuvo acompañada por un conjunto de manifestaciones de deterioro social que, contrariamente a las hipótesis o justificaciones de los diseñadores y ejecutores, fueron más allá del momento inicial del ajuste y subsisten hasta el presente: fragmentación de los mercados de trabajo con tasas altas de desempleo abierto, subempleo y sobreocupación; deterioro de las remuneraciones reales; aumento de la población en condiciones de pobreza; retracción y pérdida de calidad de la cobertura en servicios básicos; degradación ambiental; incremento de la inseguridad; fuertes desigualdades sociales. La discriminación respecto de cuánto este panorama es herencia de la etapa anterior y cuánto constituye el aporte de las reformas, cuánto representa las "asignaturas pendientes" del ajuste y cuánto es efecto sistémico del mismo, sigue suscitando discusión. Parece fuera de debate, por lo menos, que las reformas han hecho poco por revertir el panorama, y en cambio han contribuido

2. Por ejemplo Pion-Berlin (1983, 1989); Sheahan (1989) "Negocios libres y gente presa”, resumió Eduardo GALEANO (GALEANO, 1976).

3. El primero en emplear la fórmula "democracia de mercado" fue el presidente William Clinton en su discurso ante la Asamblea General de la ONU el 27 de setiembre de 1993: "Nuestro propósito conductor debe ser expandir y fortalecer la comunidad mundial de democracias de mercado", planteó en esa ocasión. Días después Anthony Lake, entonces asesor de seguridad nacional, convirtió el planteamiento presidencial en una nueva doctrina de política exterior: "La sucesora de la doctrina de contención debe ser una doctrina de ampliación (a doctrine of enlargement): la ampliación de la comunidad libre mundial de democracias de mercado" (LAKE, 1993).

4. Existe amplia evidencia empírica de que en la práctica el ajuste estructural ha requerido de un Estado fuerte, políticamente comprometido con las reformas y relativamente autónomo, sea democrático o no. Cfr por ejemplo NELSON (1989, 1990); STALLINGS (1990); LAFAY \& LECAILLON (1993). Este fenómeno puede ser interpretado como un caso particular del incremento de la acción estatal que se registra en los periodos de transición entre estilos de acumulación, y de cambios profundos en las relaciones de poder económico y político (VILAS, 1995). 
bastante a preservarlo (Altimir 1994, 1999; Jiménez 1996; Berry 1997; Morley 1998). Con más de cien países ejecutando las reformas y ajustes durante más de una década, los frutos recogidos en términos de crecimiento, sustentabilidad y bienestar son magros.

El balance del ajuste puso de relieve que no sólo en el terreno de los asuntos sociales y del bienestar los resultados distaban de ser satisfactorios. El enfoque predominantemente fiscalista de las privatizaciones determinó que las consideraciones respecto del desempeño técnico de los nuevos titulares y la calidad de los servicios ofertados mereciera menos atención que los recursos financieros que podían aportar a economías con serios desequilibrios en sus cuentas públicas. El traspaso al mercado de activos y de decisiones, y la desregulación amplia del comercio y las finanzas, dio paso con mucha frecuencia a la exacerbación de aspectos profundamente arraigados en la cultura empresarial: búsqueda de rentas, prácticas cuasi monopólicas y comportamientos clientelistas. Varios de los más importantes procesos de privatización de activos dieron lugar a sonados escándalos político-financieros y a la generación de cuasi rentas de monopolio por las firmas adjudicatarias, o por lo menos carecieron de la transparencia que la opinión pública demandaba. La modernización de la economía no fue incompatible, y a menudo encubrió, tanto la reproducción y el fortalecimiento de estructuras patrimonialistas, como la manipulación de las políticas de reforma en beneficio de grupos particulares. El "riesgo moral" en la empresa privada demostró ser tan frecuente como la corrupción del sector público y sin una correlación puntual con ésta; la eliminación de los controles públicos y la activa red de contactos empresariales informales con las agencias estatales ampliaron el espacio para que aquél alcanzara múltiples expresiones. Con cierta frecuencia las elites empresariales tradicionales o de nuevo cuño manipularon las reformas para fortalecer su propia posición de poder en el plano político y en el mercado. Por su lado, no pocas organizaciones no gubernamentales y del llamado tercer sector mostraron propensión a comportamientos clientelistas, poca transparencia en sus asignaciones y ejecuciones presupuestarias, y una fuerte dependencia respecto de fuentes gubernamentales de financiamiento externo 5 .

Estas cuestiones contribuyeron a poner en duda la razonabilidad de la hipótesis del Estado mínimo. La fe en la autoregulación del mercado no fue abandonada, pero se reconoció que un determinado ejeŕcicio de las capacidades estatales podía contribuir significativamente a mejorar su funcionamiento, o por lo menos a remover los obstáculos a tal fin. Los fracasos y las distorsiones del ajuste, y las rigideces y sesgos del mercado fueron imputadas al mal manejo de las políticas públicas o a la falta de una autoridad efectivamente desvinculada de los intereses particularistas. En esta línea de razonamiento, las fallas en el ajuste se debían, en definitiva, a problemas de ejecución, mucho más que a cuestiones de diseño o de contenido. El Estado debía ponerse a punto, y poner a punto a la sociedad, para la ejecución exitosa de las reformas.

La preocupación de los programas de ayuda al desarrollo por la calidad de la gestión pública no era novedosa.
En la segunda posguerra formó parte de las recomendaciones de política inspiradas en el Punto IV del gobierno del presidente Harry Truman, y volvió a aparecer en América Latina en los años sesenta en la agenda asociada a la Alianza para el Progreso y a algunos programas de la Agencia para el Desarrollo Internacional (AID). Resurgía ahora en un informe del Banco Mundial sobre el desarrollo del Africa meridional (World Bank, 1989), donde se afirmaba que subyacente a la persistencia de los problemas de desarrollo de Africa existía una crisis de desempeño de las agencias gubernamentales encargadas de promoverlo (p. 60). La falta de suficientes capacidades gubernamentales y la persistencia de modalidades de ejercicio patrimonialista del poder y de comportamientos estatales predatorios, eran responsables de los fracasos económicos.

En su Informe sobre el desarrollo mundial correspondiente a 1991 el Banco dedicó un capítulo específico al papel que el Estado está llamado a desempeñar en el proceso de desarrollo (Banco Mundial 1991: 150-172). Aparece aquí por primera vez la expresión "enfoque amistoso con el mercado” (market-friendly approach), aparentemente un invento del entonces vicepresidente Lawrence Summers. Por tal se entiende un estilo de intervención estatal orientada a fortalecer al mercado y optimizar su eficiencia. El informe reitera los riesgos que se derivan de la tendencia al fracaso de la gestión estatal en la economía: corrupción, rentismo, desequilibrios fiscales, inestabilidad. Reconoce, sin embargo, que la intervención del Estado no es de por sí indeseable; muchos tipos de intervención "son esenciales para que las economías cristalicen todas sus posibilidades": mantenimiento del orden público, inversión en capital humano, construcción y reparación de obras de infraestructura, protección del medio ambiente. En todas estas esferas los mercados son deficientes y la intervención del Estado se hace necesaria: no para reemplazar a los mercados, sino para fortalecerlos y complementarlos. Es imprescindible crear instituciones más eficaces, mejorar la estructura administrativa, elevar la eficiencia de las burocracias públicas, racionalizar el gasto público

5. Las reformas en las llamadas "economías en transición" (la ex URSS y el antiguo bloque soviético) constituyen ejemplos paradigmáticos tanto de la capacidad de las viejas élites políticas para metamorfosearse en una nueva burguesía gracias a la preservación de su control del poder estatal, como de la tolerancia y colaboración financiera de algunos gobiernos y agencias multilaterales occidentales. Algunos estudios informan que dos tercios de los más prominentes empresarios de Rusia, 80 por ciento de los nuevos millonarios rumanos, y la mitad de los más altos ejecutivos empresariales de Polonia, provienen de las nomenclaturas comunistas (Liebich, 1997). Menos espectacular, la manipulación clientelista de las reformas también está presente en otras latitudes. La revista especializada LatinFinance tituló su nota de tapa dedicada a la privatización de TELMEX, el monopolio telefónico estatal mexicano, "A very private affair" ( $\mathrm{N}^{\circ} 34$, Marzo 1992). En Ecuador, el vicepresidente Alberto Dahik, a cargo del programa de privatizaciones, debió abandonar el cargo y el país en medio de fuertes acusaciones de malversación de fondos, y continua prófugo desde entonces. Conaghan et al. (1990) discuten la cuasi privatización de las agencias gubernamentales en la región andina en el marco de las reformas neoliberales. CONCHEIRO BÓRQUEz (1996) presenta el caso del gobierno de Carlos Salinas de Gortari. FAZIO (1997) y ASPIAZU (1998) enfocan diversos aspectos de las relaciones particularistas gobierno/empresas en el marco de las reformas macroeconómicas en Chile y Argentina. VILAS (1996) se refiere a este tema con relación a Centroamérica. KRuItT (1992) discute los alcances, limitaciones y deformaciones de las organizaciones no gubernamentales, en el marco o como efecto, del ajuste económico. 
y descargar al Estado de las funciones y competencias que el mercado desempeña mejor, privatizando o reformando profundamente las empresas de propiedad estatal. A estos efectos el Banco recomienda impulsar reformas tributarias y del sector financiero, privatizar activos y priorizar la inversión en rubros como educación, salud, nutrición, planificación familiar y beneficencia, infraestructura, protección del medio ambiente; todo ello en un marco democrático con participación de la sociedad civil. Señala asimismo la necesidad de voluntad y compromiso político para llevar adelante el desarrollo (p. 10) e insiste en la importancia que para ello revisten la seguridad del derecho de propiedad, un régimen jurídico adecuado, un poder judicial eficiente y la supervisión de la banca.

En 1992 el Banco publicó un informe en el que destacó la relevancia estratégica de la calidad de la gestión pública para el éxito de las reformas neoliberales (World Bank, 1992). $\mathrm{El}$ autodesmantelamiento del Estado (por ejemplo desregulaciones y privatizaciones), que usualmente implica un refuerzo de la actividad estatal, demanda una gestión institucional eficaz. Según el Banco, la buena gestión pública se refiere tanto al desempeño de las agencias gubernamentales como a la promoción de la sociedad civil, entendida ésta como el conjunto de asociaciones voluntarias, no gubernamentales, involucradas en diversos aspectos de la promoción y el desarrollo social y la vida democrática. En los programas del Banco la promoción de la sociedad civil está ligada al mejoramiento de la responsabilidad, la legitimidad y la participación de los actores sociales, y a la transparencia de sus instituciones y procesos; estos factores dotan de poder a la sociedad civil y reducen el del Estado. La congruencia entre las políticas públicas y su efectiva implementación, y la asignación y uso eficiente de los recursos públicos se ve favorecida cuando los funcionarios están obligados a dar cuenta del modo en que ejercen sus funciones y son responsables de los resultados. Los gobiernos deben proveer normas legales que garanticen el funcionamiento de los mercados y protejan los derechos de propiedad. Sin un régimen de derecho estable, la suerte de las empresas y de los individuos queda librada a la voluntad de las camarillas gobernantes.

La construcción de una buena gestión pública se basa en tres niveles de transformaciones. En el nivel institucional, implica la creación de un Estado "neutral", protegido de las presiones particularistas de los actores privados y sobre todo de aquéllos más comprometidos con el régimen político-económico que se intenta reformar; en el nivel social requiere la creación de una esfera pública no gubernamental (la sociedad civil); en el nivel personal plantea la creación de un yo (self) imbuido de individualismo y de pautas modernas de conducta. El referente histórico del Banco Mundial es el proceso de modernización y desarrollo del capitalismo en Inglaterra entre los siglos XVI y XIX. Toma como ejemplo la transformación de la esfera institucional británica en el siglo XVII, con la creación del Banco de Inglaterra, una reorganización de las finanzas públicas, el aseguramiento de los derechos de propiedad, las leyes de patentes, y la liberación de los mercados (p.7).

Este documento tuvo fuerte impacto en las recomendaciones de política del Banco Mundial y de otras agencias multilaterales y gubernamentales, y en la literatura académica de los Estados Unidos. Los estudios sobre la economía política de la reforma, típicos de la segunda mitad de los años ochenta e inicios de la década del noventa, cedieron terreno a la preocupación por la ingeniería institucional ${ }^{6}$.

En 1993, después de meses de discusiones internas y de negociaciones políticas con algunos gobiernos miembro, el Banco Mundial publicó su versión del acelerado y sostenido desarrollo industrial en el sudeste de Asia (World Bank, 1993a). El documento reconoce el papel estratégico desempeñado por la intervención estatal en el lanzamiento y sostenimiento del más exitoso proceso de desarrollo capitalista de la segunda posguerra, aunque plantea la posibilidad de que similares éxitos se habrían podido alcanzar sin esa intervención; la causa fundamental del éxito del desarrollo del Asia sudoriental descansaría en su sostenida orientación exportadora, mucho más que en las modalidades de intervención estatal (p. 367) De hecho, la lectura del informe revela la intención de presentar el desarrollo de esa parte de Asia como una aplicación creativa de los fundamentos de la teoría neoclásica y del enfoque amistoso hacia el mercado, más que como otro camino para alcanzar el desarrollo. El Banco insistió en su firme adhesión a la teoría neoclásica y al enfoque del gobierno de Estados Unidos en materia de financiamiento internacional al desarrollo. De todos modos el documento admitió, aunque con renuncia, el papel desempeñado por diversas modalidades de planeamiento e intervención estatal directa que iban en contra de las premisas centrales de esa teoría: políticas sectoriales activas; selectividad crediticia; acuerdos entre agencias gubernamentales y empresas; proteccionismo a líneas de inversión promovidas; regulación de la cuenta de capital; priorización del ahorro interno como fuente principal de financiamiento de la inversión. Al mismo tiempo el informe puso énfasis en modalidades más ortodoxas de gestión pública, como desarrollo de recursos humanos y construcción y mantenimiento de infraestructura. Sobre todo insistió en los riesgos que implicaría intentar reproducir, en otras áreas del mundo en desarrollo, los estilos de relación Estado/empresas característicos del sudeste de Asia?

Estos documentos prepararon el terreno al informe sobre el papel del Estado en las reformas económicas (World Bank, 1997). Si bien debe considerárselo un desarrollo de las ideas ya formuladas en el documento de 1991, en varios aspectos este informe avanza respecto de las ambigüedades del documento sobre el desarrollo del sudeste de Asia. Reconoce la conveniencia, en ciertos casos, de una orientación estatal temporal y admite que algunos aspectos de la experiencia asiática de mercados gobernados reviste interés para las economías en desarrollo. Al mismo tiempo insiste en la primacía de los fundamentos económicos en su versión neoclásica,

6. La incorporación de la problemática institucional a los estudios del Banco Mundial se apoyó en el resurgimiento de los enfoques institu cionalistas en los estudios políticos en las universidades de Estados Unidos desde mediados de la década de 1980 y estimuló mayor desarrollo de los mismos. Vid por ejemplo EVANS, RUESCHMEYER \& SKOCPOL (1985); BREN NAN \& BUCHANNAN (1985); NORTH (1986, 1990); WEISBERG (1986); etc

7. WADE (1997) expone los pormenores de las discusiones y negociaciones que rodearon la elaboración de este estudio. 
y en la legitimación de la gestión estatal por su capacidad para ampliar los espacios de libertad de los mercados ${ }^{8}$.

El desarrollo requiere un Estado efectivo, que desempeñe un papel catalítico y facilitador, estimulando y complementando las actividades "de la empresa privada y los individuos” (pág. iii). El desarrollo dominado por el Estado ha fracasado, pero también ha fracasado el desarrollo sin Estado. "Sin un Estado efectivo, el desarrollo sostenible, tanto económico como social, es imposible” (p. 1). El Estado es central en el desarrollo económico y social en la medida que su papel sea de facilitador, socio y catalizador de la iniciativa privada, no de proveedor. Para que el bienestar humano avance, las capacidades estatales -definidas como la habilidad de emprender y promover eficientemente acciones colectivas (tales como ley y orden, salud pública e infraestructura básica- deben aumentar. La efectividad del Estado es definida como el resultado de emplear las capacidades para hacerse cargo de la demanda de la sociedad acerca de esos bienes.

Cinco tareas fundamentales componen el núcleo de la misión de cualquier gobierno, sin las cuales no es posible el desarrollo sostenible, compartido y reductor de pobreza: establecimiento de un marco legal; mantenimiento de un ambiente político no distorsionante, incluyendo estabilidad macroeconómica; inversión en servicios sociales básicos e infraestructura; protección a los vulnerables, y al medio ambiente. La fuerza distintiva del Estado en estos terrenos es su poder para imponer tributos, prohibir, castigar y requerir participación (p. 25). Un Estado eficaz se caracteriza por su capacidad para establecer las reglas en las que se sustentan los mercados y que les permiten funcionar adecuadamente. Los países con pobre capacidad estatal deberían concentrarse en la provisión de bienes públicos exclusivamente, como salud, educación e infraestructura, que generan grandes retornos en cuanto producen externalidades positivas hacia toda la sociedad (p. 52).

La reforma del Estado debe mejorar la capacidad de éste para atender los aspectos esenciales para el crecimiento económico: comercio libre, mercado de capitales libre, y desregulación de las inversiones. El Estado debe convertirse en socio y facilitador, orientando a los mercados, asegurando el cumplimiento de los contratos, garantizando la observancia de los principios de una economía sana y promoviendo el mayor desarrollo de los mercados. Con tal fin es conveniente que las agencias estatales encargadas de esta misión permanezcan protegidas de las presiones particularistas de los actores del mercado. El informe destaca la importancia de la concentración de autoridad política en algunas agencias centrales de elite: la unidad de privatizaciones dependiente de la presidencia de México en el sexenio de Carlos Salinas de Gortari (p. 63); el MITI japonés y el Economic Planning Board en Corea (p. 83). De acuerdo al Banco, en la década de 1980 Chile "parece haber desarrollado el tipo de espíritu de cuerpo entre los altos funcionarios públicos, que ha promovido asociaciones (entre agencias públicas y firmas privadas: CMV) en la tecnocracia indonesia y en el MITI japonés, entre otros”. "Más sorprendente aún son los paralelos que pueden reconocerse entre el grupo de asesores de alto nivel en Chile -los Chicago boys-, la mafia de Berkeley en Indonesia y la pandilla de los cuatro en Tailandia” (p. 83).

\section{III. ¿MÁS ALLÁ DEL “CONSENSO”?}

A lo largo de la década de 1990 el Banco Mundial argumentó respecto de la necesidad de incluir las instituciones y la gestión pública en el conjunto de cuestiones que deben ser sometidas a reforma a los fines de aumentar la eficacia de sus programas de ajuste estructural y dinamizar los procesos de desarrollo. También otros organismos multilaterales incorporaron a sus agendas la preocupación por la reforma institucional (por ejemplo, OECD 1990; UNDP, 1991). La orientación amistosa al mercado requiere mejorar el funcionamiento de las instituciones públicas y la formulación y ejecución de las políticas gubernamentales, elevar la calidad y la eficacia de la gestión estatal, así como reducir los controles políticos o fiscales y ampliar los márgenes de acción de los mercados. El ajuste económico resumido en el "Consenso de Washington" y más en general, el exitoso funcionamiento de la economía, demandan reformas profundas en el diseño y funcionamiento del aparato estatal, y no sólo la reducción de éste a su expresión mínima. La cuestión es la eficacia del Estado, una vez que éste ha alcanzado su tamaño óptimo. Esta es, se afirma, la dimensión ausente en el "Consenso de Washington".

Es posible reconocer dos enfoques de política en las propuestas de complementación, según el grado de su adhesión a la formulación original del "Consenso" y el distanciamiento respecto de las premisas fundamentales de la economía neoclásica. De manera descriptiva se hará referencia a ellos como enfoques doctrinario y pragmático. El primero plantea un conjunto reducido de reformas institucionales orientadas a mejorar la eficacia de las recomendaciones del "Consenso". El segundo cuestiona algunas de las premisas del "Consenso", señalando la necesidad de regulación estatal en terrenos en los que el mercado libre no basta para proveer desarrollo.

Burky y Perry (1998) representan claramente la posición doctrinaria". Siguiendo a North (1990), definen las instituciones como normas que configuran el comportamiento de organizaciones e individuos dentro de una sociedad. Pueden ser formales (constituciones, leyes, reglamentos, contratos, procedimientos internos de determinadas organizaciones) o informales (valores y normas) (p. 2, 11) ${ }^{10}$. El documento

8. El informe de 1997 es representativo de los cambios introducidos en las orientaciones generales del Banco Mundial con la llegada de James Wolfensohn y James Stiglitz a la presidencia y vicepresidencia, respectivamente.

9. En el momento de publicarse este documento Shahid Javed Burky y Guillermo Perry eran, respectivamente, Vicepresidente y Economista Jefe de la oficina regional para América Latina del Banco Mundial.

10. Para NorTH (1990) las instituciones son las reglas del juego, las limitaciones de cualquier tipo que los seres humanos crean para interactuar en la sociedad. Las instituciones pueden ser formales o informales. Su función principal consiste en reducir la incertidumbre estableciendo una estructura estable de interacción. El objetivo de North es elaborar una teoría de las instituciones sobre la base de las elecciones individuales. North no repara, o no asigna importancia, a la dimensión de toda institución en cuanto estructura de poder. Ni todos los seres humanos cuentan, 
pone énfasis en la reforma de las normas que determinan los incentivos, no relacionados a precios relativos, para el comportamiento de los individuos y las organizaciones. "Las instituciones eficientes deben proveer reglas claras, ampliamente conocidas, coherentes, predecibles, creíbles y uniformemente aplicadas". A su vez la capacidad de adaptación de las instituciones a las circunstancias cambiantes de la economía asegura que la estructura de incentivos se acomode a los cambios tecnológicos, las preferencias de la socie$\mathrm{dad}$, los factores externos e innovaciones institucionales en otros lugares (p. 27).

Las recomendaciones de Burky y Perry se centran en "cuatro sectores clave": finanzas, educación, justicia y administración pública. En el primero argumentan sobre la necesidad de establecer redes de protección financiera frente a las recurrentes crisis, mejorando la información a la que tienen acceso los depositantes respecto de la calidad de las operaciones y la cartera de los bancos. La red también debería reducir el riesgo moral que podría verse estimulado por la existencia de la red -en cuanto la protección que ella ofrece a los inversionistas podría favorecer comportamientos especulativos ${ }^{11}$. En materia educativa recomiendan avanzar en la reforma, dando mayor fuerza a esquemas de descentralización, privatización de las prestaciones y del financiamiento, introducción de mecanismos de competencia entre prestadores, y vinculación de la remuneración del personal docente a su desempeño. Ponen acento asimismo en la necesidad de desmontar las resistencias corporativas a una mayor reforma que pueden provenir de la acción sindical de los maestros. En el terreno de la administración de justicia recomiendan modificar la política salarial e introducir esquemas de remuneración de los jueces de acuerdo a su desempeño; la medida debería estimular la aceleración de los procesos y definir un sistema de premios y castigos pecuniarios que diferencie entre jueces eficientes e ineficientes. El sistema legal, inspirado en el modelo francés, debería ser sustituido por un esquema más ágil, que brinde mayor protección a los derechos de las minorías en materia económica y financiera. Finalmente, en materia de administración pública recomiendan mayor impulso a la descentralización, estímulo a la transparencia, desarrollo de modelos alternativos de gestión que mejoren la calidad de las respuestas a las demandas del mercado y la sociedad.

En su versión doctrinaria las propuestas de avanzar "más allá del Consenso de Washington" deben ser vistas como intentos de complemento del "Consenso", más que como hipótesis de políticas alternativas; se advierte fácilmente su vinculación con las recomendaciones formuladas en el informe del Banco Mundial de 1991, resumido en la sección anterior. Se trata básicamente de encarar las que se estima tareas pendientes del ajuste y de mejorar la implementación de las políticas, de ahí la necesidad de la reforma institucional. Son acciones de política que figuran desde hace años en la agenda de las reformas de tipo neoliberal; el aporte de Burky y Perry consiste, más que en una innovación sustantiva, en la recolección de un número de acciones dispersas bajo una denominación sencilla y de amplia acogida.

Desde una perspectiva pragmática, aunque sin romper lanzas con los postulados básicos de la economía neoclásica,
Joseph Stiglitz (hasta hace poco vicepresidente del Banco Mundial) admite que el buen funcionamiento de los mercados requiere políticas de regulación fiscal, fomento de la competencia, desarrollo de la educación, estímulos a la transmisión de tecnología y fomento de la transparencia, temas todos ausentes del "Consenso de Washington". Hacen falta políticas específicas. El Estado debe complementar al sector privado y la actividad estatal debe ser más efectiva. La privatización sin fomento de la competencia y sin regulación favorece la búsqueda de rentas. En esto la empresa privada no es distinta de la empresa estatal. La cuestión central es el monopolio u oligopolio, no el tipo de derechos de propiedad: "la importancia de la competencia es mayor que la de la propiedad". A no ser que la economía sea de verdadera competencia, los beneficios del libre comercio y la privatización serán disipados en la captura de rentas y no dirigidos a la creación de riqueza. Si la inversión pública en recursos humanos y transferencia de tecnología son insuficientes, el mercado por sí solo no llenará la brecha”. Hacer funcionar bien los mercados "requiere algo más que una baja inflación; requiere regulación fiscal, políticas para la competencia, políticas que faciliten la transmisión de tecnología y promuevan la transparencia, por sólo citar algunos aspectos no tratados por el Consenso de Washington" (Stiglitz, 1998).

La posición de Stiglitz es más novedosa en cuanto al enfoque de las relaciones Estado/mercado, que en lo referente a acciones concretas de política. Por esto mismo, implica un cuestionamiento mayor del "Consenso". Las experiencias exitosas de desarrollo en el sudeste de Asia han ejercido influencia en el reexamen de las relaciones Estado/mercado aquí recomendado, por más que se reconoce que no existen al respecto recetas o recomendaciones genéricas válidas para todo el mundo o en todo lugar (vid. también Stiglitz, 1997)

\section{DISCUSIÓN}

El carácter estratégico de la intervención estatal para la superación del atraso económico es admitida por la teoría económica por lo menos desde el estudio de Veblen (1915) sobre el desarrollo industrial de Alemania y la posterior ampliación de su tesis por Gershenkron (1962) ${ }^{12}$. En esta línea de pensamiento, la investigación de Johnson (1982) sobre el MITI japonés, y una nutrida producción académica posterior, destacaron el papel de varias agencias gubernamentales en la exitosa promoción del desarrollo en varios países del sudeste de Asia. Existe una coincidencia amplia, en estos análisis, en reconocer que un marco institucional eficiente mejora las perspectivas de éxito de las políticas

en términos efectivos, con la misma capacidad para crear instituciones, ni la creación institucional es simplemente un acto de racionalidad individual.

11. La necesidad de reducir la especulación financiera y dotar de mayor responsabilidad a los bancos y a los inversores se encuentra presente en algunas iniciativas recientes del FMI -por ejemplo, el "Código de Basilea” sobre comportamiento y responsabilidades bancarias, y recomen daciones de complementación entre los sectores público y privado. Cfr también FISCHER (1999).

12. Vid también Kitching (1982) y PiPITONE (1994)-quien plantea una interesante distinción entre atraso económico y subdesarrollo (pp. 26-28) 
estatales, aunque hay tendencia a soslayar las diferencias nacionales en materia de arreglos institucionales y de instrumentos de gestión, para identificación de un modelo regional. Más que las similitudes o coincidencias en los instrumentos, destaca en las experiencias exitosas del sudeste de Asia la estrecha vinculación de la gestión pública a un conjunto de grandes objetivos nacionales que orientaron la acción del gobierno y modelaron la construcción institucional (cfr. Weder, 1999).

Desde la perspectiva de la teoría política, una gestión pública de alta calidad se fundamenta en los principios básicos de un régimen democrático, aunque la relación entre calidad de la gestión y tipo de régimen político dista mucho de ser unívoca. La responsabilidad pública de los funcionarios, el acceso de los ciudadanos a información gubernamental, el control popular de las acciones de gobierno, la separación entre el patrimonio público y el patrimonio de los funcionarios, la tributación como obligación ciudadana, son todos ingredientes de un régimen político que apuntan, entre otras cosas, al buen uso de los recursos públicos, algo que usualmente se asocia con la democracia y el buen gobierno. En particular hay que mencionar la vinculación, que se remonta por lo menos al siglo XIII, entre participación política y tributación. En cuanto el financiamiento del Estado proviene siempre, en definitiva, de los recursos que extrae de la sociedad, existe una obligación legal e incluso ética de los funcionarios de dar un uso correcto al producto de esa exacción -vale decir, asignándoles el destino definido por los ciudadanos y sus representantes, y gestionándolos con eficiencia ${ }^{13}$.

En líneas generales, el sector público en América Latina presenta déficit serios en materia de eficacia, eficiencia, asignación de recursos, transparencia en la ejecución de los mismos, alcance y oportunidad de los mecanismos de fiscalización y control. La necesidad de encarar estas cuestiones se apoya tanto en los principios básicos de un régimen democrático o en la funcionalidad de una buena administración como, de manera más inmediata, en los compromisos financieros externos asumidos por la mayoría de los gobiernos, que demandan una severa racionalización fiscal. Señalar las deficiencias del sector público no debería llevar a pensar que el sector privado está libre de problemas, por más que en años recientes tanto en el terreno de la política como en el de la academia sea más notoria la preocupación por aquéllas que por éstos ${ }^{14}$. Fácilmente se advierte que unas y otras no se compensan ni se disculpan recíprocamente, más bien se potencian. La discusión crítica de las propuestas de reforma institucional del Banco Mundial y de los alcances y limitaciones reales de la afirmación de ir "más allá del Consenso de Washington", que se presenta en esta sección, no debería ser entendida, por lo tanto, como una justificación, mucho menos una defensa, de lo malo realmente existente.

\section{Política y administración}

Destaca en los documentos del Banco Mundial, ante todo, la reducción del Estado a su dimensión operativa de gestión pública. Es éste un aspecto característico de todo actor instalado en la cúspide del poder político en momentos de grandes cambios en la sociedad y en el Estado, y tiene poco que ver con ideologías particulares. "Para que las "armonías económicas" subsistan la ciencia política no debe preocuparse por la organización del Estado, sino simplemente de su función”, expresó Fréderic Bastiat, el filósofo liberal de la economía (apud Sampay 1944: 57). Su recomendación acopla bien con la utopía marxista de "sustituir el gobierno de los hombres por la administración de las cosas" (Marx, 1859) y la burocratización de la conducción política en los regímenes de tipo soviético. Ambas reaparecen en los intentos de proscripción de la actividad política no gubernamental por las dictaduras militares de las décadas pasadas en Brasil, Chile o Argentina, y en las afirmaciones contemporáneas del fin de la política (por ejemplo Mulgan, 1994; Guehénno, 1995).

En virtud de este reduccionismo, el Estado queda vaciado de política en cuanto ésta es ante todo construcción, ejercicio y discusión del poder. La atención se dirige fundamentalmente al funcionamiento de las instituciones públicas; la problemática propiamente política de la construcción estatal y del desarrollo es diluida y remplazada por la cuestión de la administración de una determinada configuración de poder que se supone constante. La discusión de los grandes objetivos de la acción política -el desarrollo, el bienestar, la integración social, u otros- se desplaza hacia el comentario y las recomendaciones sobre el modo de desempeño de los instrumentos y la administración de los recursos. En este enfoque, los actores significativos de la acción política son siempre actores estatales: burocracias civiles y militares y, en general, personal dotado de determinadas destrezas técnicas. La "política desde abajo", vale decir, la que corre por cuenta de los actores no estatales, se legitima y es promovida en la medida en que complementa a la que se ejerce desde el Estado en función de los objetivos perseguidos o tolerados por éste.

Al contrario, desde una perspectiva más dinámica, el Estado es ante todo la institucionalización de las relaciones de poder en la sociedad y de su articulación con el sistema internacional de relaciones políticas, comerciales y financieras. Esta dimensión sustantiva se hace explícita y se desenvuelve en el funcionamiento cotidiano de las agencias públicas (gobierno central, tribunales, etc.) y en sus múltiples relaciones con la sociedad y el mercado. Ello no significa que en el nivel orgánico o institucional el Estado se presente siempre como una unidad homogénea; instituciones particulares pueden expresar y movilizar diferentes arreglos sectoriales de poder. Existe, sin embargo, una coherencia básica que mantiene el potencial de conflicto entre agencias -y entre

13. BRESSER PEREIRA (1999a, 1999b:83-97) resalta la vinculación entre uso correcto de los recursos públicos y derechos de ciudadanía, aunque para ello no es necesario, como plantea Bresser, una reformulación de la teoría de la ciudadanía o la identificación de unos derechos republicanos diferentes de los derechos ciudadanos.

14. Caso ilustrativo de este sesgo es GIDDENS (1998). En su propuesta de una "tercera vía" para la socialdemocracia europea, Giddens se explaya sobre las necesidades de reforma y modernización del Estado y de la sociedad civil, con interés considerablemente menor respecto del mercado y el mundo de las empresas. 
los arreglos de poder que ellas institucionalizan- dentro de márgenes aceptables de gobernabilidad ${ }^{15}$.

El modo en que un Estado lleva a cabo la administración de sus recursos y la gestión de sus políticas es analíticamente diferenciable de esos arreglos de poder, pero guarda respecto de ellos una relación de adecuación básica. Las capacidades de gestión estatal tienen como referencia y horizonte los objetivos de la acción política, y éstos siempre expresan, de alguna manera, los intereses, metas, aspiraciones, afinidades o antagonismos del conjunto social y de la jerarquización recíproca de sus principales actores. No existe un tamaño óptimo del Estado -sea "mínimo", "máximo" o de otra índole- al margen de los actores sociales que determinan su comportamiento y de los objetivos que los orientan. La relación entre la gestión pública, la estructura socioeconómica y las orientaciones políticas del Estado siempre es estrecha ${ }^{16}$. Los estilos de gestión de los recursos públicos, y la conceptualización misma de ciertos recursos como públicos, guardan una vinculación íntima con los objetivos a los que apunta dicha gestión y, por lo tanto, con la configuración de la estructura de poder de la que esos objetivos derivan. Así, el esquema de gestión burocrática es típico de escenarios sociopolíticos de relativa estabilidad y autonomía operativa del Estado respecto de una sociedad de masas con conjuntos sociales de cierta homogeneidad. Al contrario, un esquema de gestión de tipo gerencial usualmente responde a la necesidad de adaptación rápida a escenarios cambiantes de públicos segmentados, preeminencia de los tiempos cortos, toma de decisiones con interpretación y aplicación flexibles de marcos normativos laxos, e incluso ausencia de marcos normativos.

La gestión de las relaciones laborales entre empresas y trabajadores ofrece una buena ilustración de la vinculación entre esquemas de administración pública y relaciones y jerarquías sociales. El desarrollo del derecho del trabajo, como rama específica del derecho público, fue resultado de una configuración de relaciones de poder entre sindicatos y empresas en el marco de una sociedad de masas, esquema fordista de producción y creciente regulación estatal. La creación de este cuerpo legal ensanchó las modalidades de mediación estatal; dio pie al desarrollo de nuevas agencias gubernamentales y ramas de administración de justicia; limitó las facultades decisorias de las empresas; acotó la capacidad de acción de las organizaciones laborales y contribuyó al fortalecimiento de una ideología de derechos colectivos que coexistió con desiguales niveles de conflictividad con la concepción liberal tradicional de derechos individuales. La progresiva sustitución del derecho laboral por el derecho civil o comercial, en cambio, testimonia en nuestros días el retroceso de la capacidad de afiliación y de negociación de los sindicatos de trabajadores; junto con el predominio de esquemas de acumulación flexible, desregulación amplia de la economía, recuperación de capacidad decisoria por las empresas y resurgimiento de una ideología de racionalidad individualista. El cambio de marco jurídico implica asimismo una transferencia de la gestión de las relaciones laborales del ámbito público al privado.

En la discusión de estos asuntos conviene tener presentes dos consideraciones generales. La primera es que la eficacia de la gestión pública requiere, en cada escenario institucional y sociopolítico, la consistencia del diseño de las políticas con los objetivos que se persiguen, así como coherencia en la gradación o jerarquía que se reconoce entre ellos. El diseño de las políticas públicas es, fundamentalmente, un tema de técnicas e instrumentos; lo segundo es, ante todo, materia de la política en cuanto ésta se refiere al deber ser del desempeño público. Es también materia de la política la elección entre diferentes opciones instrumentales. La otra consideración se refiere a la eficiencia de las políticas públicas. Eficiencia es en el fondo una cuestión de costo/beneficio, de definición de criterios respecto de cuánto se está dispuesto a pagar para alcanzar determinados resultados, de qué naturaleza son los costos a considerar (económicos, políticos, de prestigio, etc.) y de quién o quiénes deberán hacerse cargo de ellos. Ésta es también una decisión eminentemente política en cuanto siempre tiene como referente las relaciones de poder entre determinados actores y de éstos con relación al Estado; se sabe desde hace mucho tiempo que una de las manifestaciones más claras del poder político consiste en la capacidad de hacer pagar a otros los costos de las acciones encaminadas a alcanzar los objetivos de quien lo ejerce. La naturaleza política de ambas cuestiones no se diluye por el hecho de que las respectivas decisiones se deleguen hacia funcionarios que ocupan posiciones formalmente técnicas, o hacia actores del ámbito privado.

Puede argumentarse que, por su propia naturaleza, un organismo multilateral carece de mandato para involucrarse en aspectos sustantivos como los señalados. De acuerdo con esta interpretación, los organismos actuarían en definitiva como cajas de resonancia de cada gobierno, aceptando $y$, eventualmente, fortaleciendo con sus recomendaciones la correlación de poder prevaleciente en cada país solicitante de asesoría o fondos: una misión eminentemente conservadora. La enorme capacidad de persuasión de las recomendaciones de los organismos no derivaría de los recursos que movilizan o de la presión que pueden ejercer sobre los gobiernos, sino de su habilidad para acoplarse a decisiones ya adoptadas por las autoridades políticas -algo así como navegar a favor del viento. El argumento trasluce una visión incompleta del desempeño de estos organismos y de sus relaciones con los estados miembros. No es un secreto para nadie que las recomendaciones de política pública formuladas por el FMI, el Banco Mundial, el BID y organismos similares, inciden decisivamente en la matriz de poder de la sociedad, promoviendo a algunos actores, discriminando contra otros, y en definitiva interviniendo en la dinámica política y social en nombre de una racionalidad técnica o de los macroeconomic fundamentals. En algunas situaciones de gran conflictividad política y social, las condiciones impuestas por estos organismos para el desembolso de fondos reforzaron la posición del gobierno de Estados Unidos en su confrontación con gobiernos de países en desarrollo; las presiones ejercidas sobre el gobierno de Michael Manley en Jamaica siguen siendo un caso de estudio en algunas universidades

15. Vid en ViLAS (1997a) un desarrollo de estas proposiciones

16. BROWN (1981:265) se refiere a ella como una relación "claramente simbiótica". 
de Estados Unidos y Canadá. A la inversa, el financiamiento amplio a algunos países contribuyó a mantener en el poder a regímenes autoritarios dilapidadores de recursos a los que la política exterior de Estados Unidos consideraba aliados en el marco de la guerra fría -Indonesia es, posiblemente, el caso más notorio (Payer, 1982a, 1982b; Huber \& Stephens, 1986; George \& Sabelli, 1994).

Viene al caso regresar al ejemplo de las relaciones laborales. Es notorio que la insistencia de algunos organismos en la flexibilización laboral ajusta mucho mejor con las orientaciones de algunos de los participantes en la negociación laboral, que con las de otros. En este orden de ideas, la encuesta elaborada por el Banco Mundial para dotar de base empírica a las recomendaciones sobre la relación Estado/mercado contenidas en el informe de 1997 es ilustrativa de lo que podría conceptualizarse como un sesgo político de clase (World Bank, 1997: 174-175). La encuesta se refiere exclusivamente a las opiniones emitidas por empresarios; deja de lado la opinión de trabajadores así como la de la población agrupada en un amplio arco de organizaciones sociales que también tienen puntos de vista respecto de aquella articulación: organismos vinculados a la protección del ambiente, asociaciones de consumidores o de usuarios de servicios públicos, organizaciones de defensa de los derechos humanos, etcétera. No es claro el modo en que el Banco compatibiliza este sesgo con los enunciados de sus informes de 1991 y 1992, ya comentados, respecto del fortalecimiento de la sociedad civil como dimensión integral del proceso de desarrollo. Sin embargo la inclinación a prestar oído a ciertos actores sociales o económicos en detrimento de otros es consistente con la base de datos movilizada en la elaboración del informe correspondiente a 1995. Dedicado al análisis de las transformaciones de los mercados de trabajo y al futuro del empleo, no es evidente que el Banco haya tenido en consideración la opinión o las reflexiones de trabajadores o de organizaciones laborales (Banco Mundial, 1995) ${ }^{17}$.

\section{Instituciones formales e informales}

El enfoque formalista de las instituciones propuesto por Douglass North, que el Banco adopta explícitamente (World Bank, 1997), permite referirse a la política en tanto construcción y procesamiento de relaciones de poder, y operar sobre ella, afectando la presidencia. La caracterización de una institución como un sistema de reglas del juego soslaya cuestiones fundamentales como el contenido del juego, la finalidad del mismo, el número e identidad de los participantes, la existencia o inexistencia de árbitro y similares. También deja de lado la circunstancia, bastante evidente, que no todos los individuos o grupos se encuentran en igualdad de condiciones para crear o imponer determinadas instituciones, o para decidir la medida y el sentido de su participación en ellas. A diferencia de los modelos elaborados en teoría de juegos, en la sociedad real los diferentes jugadores tienen una desigual dotación de recursos, y capacidades desiguales de movilizarlos cuando el desenvolvimiento del juego lo requiere; es sabido, asimismo, que estas desigualdades alcanzan en América Latina niveles mayores que en el resto del mundo (CEPAL, 1997; BID,
1998). El tránsito recién señalado, de un esquema tripartito de gestión de las relaciones laborales a otro de tipo bilateral, ilustra sobre un cambio institucional que afecta explícitamente la eficacia decisoria de los actores directamente involucrados en uno y otro modelo.

En cambio, el Banco no extrae suficiente rendimiento de la diferenciación entre instituciones formales e informales (North, 1990, caps. I y V). La distinción entre unas y otras es en realidad mucho menos tajante que lo que North supone. El marco formal del poder político y económico existe junto a una variedad de estructuras informales que se entrecruzan con él, lo complementan y se desenvuelven de manera paralela. Esas estructuras informales se suman al sistema formal, actúan en los espacios que éste no cubre y hacen posible el funcionamiento de sus grandes instituciones. "La integración de la sociedad global requiere del tejido menudo de estas relaciones intersticiales" (Wolf, 1966). Algunos de los resultados efectivamente recogidos por el "Consenso de Washington", indicados en la sección II, ilustran de manera explícita la combinación conflictiva a veces, complementaria otras, entre instituciones formales e informales: por ejemplo la persistencia de redes clientelares en el marco de la modernización institucional; orientaciones particularistas en la asignación de recursos; o privatizaciones por asignación directa de los activos a actores próximos a la alta función pública, sin contralor institucional. Estos ejemplos indican, además, que la informalidad no es una característica exclusiva de un sector precario o de pequeña escala, sino una dimensión que puede estar presente en cualquier tipo de negocios (cfr. de la Peña, 1996).

La consideración de los modos y alcances de la gravitación de las instituciones informales en los procesos de desarrollo introduce la cuestión del tiempo largo no lineal que caracteriza la dinámica de éstas. "Aunque las normas formales pueden cambiar de la noche a la mañana como resultado de decisiones políticas o judiciales, las limitaciones informales enraizadas en costumbres, tradiciones y códigos de conducta son mucho más resistentes o impenetrables a las políticas deliberadas. Estas limitaciones culturales no solamente conectan el pasado con el presente y el futuro, sino que brindan una clave para explicar el derrotero del cambio histórico" (North 1990:16) ${ }^{18}$. Este ritmo de desenvolvimiento contrasta con las urgencias de las agendas de reformas y su orientación explícita hacia la producción de resultados en el corto plazo, y con los cronogramas de los organismos que tienen a su cargo la auditoría de los programas de reforma y de los gobiernos que los ejecutan.

17. Los informes de país (country reports) suelen ser más explícitos en su enfoque amistoso hacia determinados actores y arreglos de poder. Se trata de documentos redactados para funcionarios políticos y técnicos que, a diferencia de los informes generales, raramente están al alcance de un público más amplio. Por ejemplo: a pesar de que la fuerte concentración de la tenencia y propiedad de la tierra sigue siendo uno de los aspectos centrales de los conflictos sociales y políticos en El Salvador, y una de las fuentes mejor conocidas de generación de pobreza, ni siquiera un párrafo ha sido dedicado a esta cuestión en el informe del Banco Mundial sobre el combate a la pobreza en ese país (vid WORLD BANK 1993b).

18. Sobre tiempo corto y tiempo largo, tiempo lineal y tiempo no lineal en los procesos económicos y sociales vid SCHELLING (1973); Pro NOVOST (1989); IBARRA (1996). 
El tipo de cambio, la política crediticia, la desregulación comercial o la liberalización de los precios pueden decidirse en un tiempo corto y generan efectos de inmediato; otra cosa ocurre con la reconversión productiva, la formación de recursos humanos, el desarrollo científico-técnico o una ética de responsabilidad pública.

El enfoque ahistórico de las propuestas de reforma y su propensión a la imitación de modelos de organización institucional agrava estas tensiones. El informe del Banco Mundial de 1997, dedicado a "lo que el Estado debería hacer, cómo debería hacerlo, y de qué modo puede hacerlo de la mejor manera" (World Bank, 1997: 1-3) adopta explícitamente un enfoque abstracto que no reconoce las diferentes matrices de articulación entre el Estado y las estructuras sociales y económicas, ni las trayectorias históricas que desembocan en los escenarios contemporáneos. La idea de que la construcción institucional forma parte integral de la vida de una sociedad, y que el desempeño efectivo del marco institucional es resultado de un conjunto muy amplio de transacciones entre actores sociales, no parece figurar en el repertorio intelectual de los funcionarios que diseñan las reformas, o por lo menos de los que escribieron el informe. Se advierte, por lo tanto, resistencia a admitir la posibilidad de trayectorias diferenciadas en el desarrollo de las economías -según se vio en la discusión del desarrollo en el sudeste de Asia en el informe de 1993. La adhesión a un determinado marco teórico -la economía neoclásica- se combina con un modelo etnocéntrico de desarrollo social que en definitiva remite al caso histórico particular de algunas áreas de Europa occidental. Es éste un tema ampliamente debatido respecto del cual no es necesario insistir (cfr. Browett, 1985; Leftwich, 1994; Gills \& Philip, 1996).

Una importante literatura señala las complejas dimensiones históricas y culturales de los procesos de construcción y cambio institucional (por ejemplo Hintze, 1931; Polanyi, 1957; Corrigan \& Sayer, 1985; Poggi, 1990; Tilly, 1992). La formación y las transformaciones del Estado moderno en el marco del desarrollo histórico del capitalismo implican formas específicas de concebir nociones básicas de autoridad y legitimidad, y de referir los comportamientos individuales y del grupo inmediato a conjuntos humanos más amplios y a marcos normativos impersonales -la dominación racional legal de la sociología weberiana. En último análisis involucra la internalización en cada persona de una antropología filosófica que destaca al individuo como agente autónomo de los procesos sociales (Sayer, 1991; Callinicos, 1999: 10-38). El desarrollo de una racionalidad individual y de las instituciones que le sirven de soporte - en primer lugar, el mercado como forma generalizada de interacción y de regulación social- no es espontáneo ni tiene lugar de manera homogénea en todos los ámbitos de la convivencia humana. Que una persona llegue a asumirse a sí misma como individuo y a orientar, en consecuencia, la totalidad de su conducta y sus interacciones, es resultado de un prolongado proceso en el que interviene una pluralidad de factores, incluyendo momentos de extraordinaria coacción física y simbólica. La extensión de esta racionalidad desde algunas ciudades del norte y el centro de Europa hacia el resto del mundo a partir del siglo XVII está estrechamente asociada a cuestiones como la expansión del comercio, desarrollos científico-técnicos aplicados a la producción y la guerra, la centralización del poder político, el sistema de escuelas públicas, la constitución de vastos imperios coloniales y el ejercicio de la violencia física en modalidades desconocidas.

La promoción de la racionalidad individualista por las reformas económicas e institucionales del "Consenso de Washington" y sus complementos, demanda modificaciones radicales en los hábitos, percepciones y valoraciones de conjuntos amplios de la población. Se trata de sustituir el concepto de derechos y obligaciones colectivas -emanadas unos y otras, tanto de tradiciones comunitarias como de concepciones socialdemócratas- por la noción de capacidades individuales referidas fundamentalmente al mercado como sistema de organización social. El referente implícito es un modelo de elección racional de individuos orientados por una motivación utilitaria, con libre e igual acceso a la información. En sus versiones más fundamentalistas el rediseño neoliberal de las instituciones apunta a una reconfiguración cultural profunda del conjunto de la sociedad y a la reducción de ésta a una sumatoria de interacciones individuales de motivación egoísta - "la sociedad no existe", según el dictum atribuido a Margaret Thatcher y retomado por algunas vertientes de la literatura postmoderna (Laclau, 1991). La Bolivia de inicios de la década de 1990 ilustra con dramatismo las violentas reacciones que estos tardíos intentos cuasiiluministas suelen suscitar. La ejecución de las reformas durante la presidencia de Gonzalo Sánchez de Losada demandó en Bolivia el establecimiento del estado de sitio: la suspensión de las garantías individuales como condición para la implantación de la ideología del individualismo. Los acontecimientos registrados recientemente en Ecuador aportan más evidencia en el mismo sentido. Debe señalarse que el impacto cultural de estas propuestas no se limita a las sociedades multiétnicas o multiculturales. Todo arreglo, más o menos estable, de poder tiende a generar un conjunto amplio de actitudes, comportamientos, expectativas y valoraciones. Las modificaciones de tales arreglos, implícitas en las propuestas de reforma institucional, chocan contra esos patrones culturales y generan resistencias y reacomodos. Tiene lugar un trastrocamiento de los criterios aceptados de lo que es justo y lo que no lo es. Estos criterios se ubican en la base de las prescripciones sociales de la convivencia y tienen un ritmo propio de transformación; la imposición de modificaciones en el tiempo corto incrementa los niveles tolerados de incertidumbre y alimenta el malestar social.

La euforia modernizante de algunos reformadores identifica al conjunto de instituciones "tradicionales" y a su ritmo diferente de cambio con el atraso, y con frecuencia define un antagonismo de principio con ellas. Ciertamente, la implantación del mercado como forma dominante de organización social encuentra resistencias en muchos de los patrones previos de organización. Además, la defensa de la tradición o de "las cosas como son" puede encubrir o justificar las formas de injusticia, opresión y explotación típicas de esos conjuntos sociales en nombre del respeto al multiculturalismo. Un enfoque más integrado y posiblemente sensato de los procesos de transformación social-aunque menos 
motivado por urgencias financieras- permitiría advertir, sin embargo, que en muchas de las instituciones basadas en la solidaridad, la cooperación o la reciprocidad se encuentran presentes fuerzas y tendencias que podrían potenciar modalidades menos traumáticas de modernización, o que estructuras e instituciones convencionalmente tradicionales pueden actuar como detonantes de procesos de cambio de grandes proyecciones (cfr. por ejemplo Rudolph \& Rudolph, 1967; Stephen, 1991; Mazlish, 1991; Tarrow, 1994).

En los países industrializados estos procesos de transformación institucional y cultural demandaron décadas de prueba y error y de adaptación, e involucraron costos sociales importantes; en respuesta a ellos, la sociedad primero y el Estado después, pusieron en funcionamiento una variedad de instituciones e instancias de contención y de compensación, desde las primitivas sociedades de beneficencia hasta los modernos sistemas de seguridad y promoción social. El Banco Mundial se desentiende de esta evidencia en sus recomendaciones de reforma, así como del fracaso de los mecanismos tradicionales de contención y de la cuestionable eficacia de los que son propuestos como sustitutos (Vilas, 1997b). La intención de promover el cambio institucional a ritmo acelerado, sin mayores consideraciones sobre el terreno social en el que las nuevas instituciones deberían desenvolverse, se asemeja a ciertas políticas de importación de equipamiento "llave en mano". Se instala el producto final, omitiendo el desarrollo histórico que condujo a él y el entrenamiento social que ese desarrollo favoreció. El resultado de estos injertos suele agravar las deformaciones y fragmentaciones típicas del subdesarrollo, con la coexistencia de polos o enclaves de modernidad integrados a las economías más desarrolladas, y grandes espacios de baja productividad y poco valor estratégico para las líneas más dinámicas de la economía nacional y su inserción externa. Del mismo modo, la atención prestada a la modernización de los ámbitos de la gestión pública más vinculados con las áreas del mercado o de la sociedad más relevantes en el esquema dominante de organización económica y social (por ejemplo, sector financiero, comercio exterior, seguimiento y control de grupos específicos de población) coexisten con el atraso, la ineficiencia y la desatención hacia la gestión pública referida a actores y cuestiones no estratégicas para ese mismo esquema: por ejemplo medio ambiente, tercera edad, protección de los consumidores, seguridad y asistencia social. Estas asincronías ilustran la capacidad de las sociedades dominantes y de los actores de mayor gravitación en los procesos de acumulación, en el desarrollo científico y técnico y en el ejercicio del poder político, para imponer al resto sus propios ritmos y estilos de cambio (Toulmin y Goodfield, 1968; Ramos Torre, 1992). También en este aspecto la experiencia de aprendizaje y de adaptación creativa que caracteriza a los procesos exitosos de desarrollo de Japón y el sudeste de Asia, ofrecen algunas enseñanzas que no parece prudente desaprovechar (vid. por ejemplo Morris Suzuki, 1998). Tanto más cuando en el propio mundo anglosajón se está fortaleciendo un arco muy variado de propuestas de ética social comunitaria o, para recurrir a un lenguaje de moda, "post-individualista".

La privatización de los sistemas de seguridad social brinda una buena ilustración de las limitaciones de una política de imitación institucional que desatiende los entornos socioculturales. El ejemplo es particularmente adecuado porque en este tema el planteamiento del Banco Mundial trató de hacerse cargo, con particular atención, de varias de las discrepancias empíricas de las sociedades en desarrollo respecto de algunos modelos teóricos. En el marco del "Consenso de Washington" la privatización de los sistemas de jubilaciones y pensiones es vista como un elemento que permitirá aumentar el ahorro interno y dinamizar los mercados de capital; se presenta asimismo como una forma de superar las ineficiencias y limitaciones de los sistemas de reparto. El sistema tiene en cuenta la experiencia de los fondos de pensión de Estados Unidos y otros países del mundo anglosajón -y en menor medida de Japón y los países escandinavos- y se apoya en la teoría del ciclo de vida enunciada por Franco Modigliani y otros. La evidencia de que las sociedades en desarrollo muestran marcadas diferencias empíricas respecto de algunos de los supuestos del modelo -por ejemplo, la informalidad, inestabilidad y fragmentación de los mercados de trabajo en los que actúa una porción importante de la población reducen significativamente la previsibilidad e incluso el desenvolvimiento de un ciclo de vida como el que la teoría adopta como supuesto; el modelo implícito de organización familiar no se compadece con la variedad de estructuras familiares observables en la región; etc.- llevó al Banco Mundial a elaborar un modelo más acorde con esos escenarios (World Bank, 1994) ${ }^{19}$.

Los alcances y limitaciones de esta propuesta y de sus aplicaciones siguen siendo objeto de fuerte debate. Se quiere destacar aquí que, como no podía ser de otra manera, el desempeño de las firmas administradoras de fondos de seguridad social en los mercados latinoamericanos es manifiestamente diferente que en el mundo anglosajón, en varios aspectos: comisiones por servicios considerablemente más altas; tasas de ganancia más elevadas sin perjuicio de coberturas mucho más reducidas; líneas de inversión más orientadas hacia colocaciones de corto plazo en detrimento de opciones más convencionales y seguras (por ejemplo infraestructura o vivienda) aunque con tasas de retorno más reducidas. No se advierte en los gobiernos de la región la definición de estímulos que orienten las colocaciones financieras hacia objetivos de desarrollo, mientras que los proyectos de inversión en infraestructura, desarrollo social, etc. siguen dependiendo fuertemente de financiamiento externo. Ninguno de estos factores ha sido tenido en consideración en la propuesta del Banco. Además, la prestación básica resulta un pobre complemento de los mecanismos de solidaridad familiar o comunal, y los elevados niveles de evasión tributaria (incluyendo las contribuciones obligatorias a la seguridad social) conspiran contra un adecuado financiamiento. Así como en el sistema de reparto fue frecuente observar la primacía del objetivo de financiamiento del déficit

19. El modelo del Banco Mundial contempla tres tipos de aportes una prestación básica, obligatoria, administrada por el Estado y financiada vía impuestos, que cumpliría un papel equivalente al de los sistemas informales de seguridad (desempeñados por las redes de parentesco y otras redes de solidaridad), un pilar de ahorro privado obligatorio administrado por firmas privadas y sujeto a capitalización, y fondos provenientes del ahorro privado voluntario también administrados por el sector privado. 
fiscal, existen razones para pensar que en los esquemas privatizados prima la racionalidad de desarrollo del mercado de capitales y su internacionalización, por encima de la calidad y el alcance de la cobertura de los riesgos.

La violencia proactiva o reactiva de la implantación de los nuevos modelos suele ser directamente proporcional a la velocidad con que la implantación se pretende, cuestión ésta que vuelve a ubicar el tema en el marco de las diferentes concepciones de la temporalidad. La sustitución de patrones culturales de tipo comunitario tradicional por otros de tipo mercantil individualista; el remplazo de vinculaciones de tipo consuetudinario por otras de naturaleza contractual; o el paso de orientaciones y estilos de tipo corporativo a otros de tipo concurrencial, demandan períodos de adaptación usualmente más prolongados que los que forman parte de la contabilidad comercial y de la valorización del capital (cfr. Safa, 1993; Williams \& Young, 1994; Santiso, 1997). Afortunadamente no todo es violencia, aunque el recurso a la coacción estatal, o a acciones de protesta social, adquieran siempre mucha notoriedad. Más usual es la enorme variedad de comportamientos adaptativos y de reciclaje de las nuevas instituciones en términos de las prácticas convencionales, incluso en sus manifestaciones más perversas. Así, es común encontrar que las propuestas de descentralización administrativa, inspiradas en criterios de participación social, tienden a reforzar el poder de las élites locales y de estilos caciquiles de dominación. Otras veces, la estrategia de "desatar las manos de los administradores" para dotar de mayor agilidad a la gestión pública ha dado lugar a situaciones de arbitrariedad por ausencia o ineficacia de mecanismos adecuados y oportunos de fiscalización. Con bastante frecuencia los programas sociales focalizados para llegar "a quienes más los necesitan" han sido instrumentalizados con fines electorales o como retribución de lealtades políticas ${ }^{20}$.

\section{Una cuestión de gobernabilidad}

El interés en una buena gestión pública muestra sensibilidad hacia la problemática de la gobernabilidad de los procesos de reformas en los escenarios de astringencia fiscal que predominan desde los años ochenta. Las alteraciones sociales y económicas y las modificaciones en las relaciones de poder ponen en tensión las capacidades de orientación y gestión gubernamental y obligan a una reformulación de las mismas. No es casual que reforma institucional y gobernabilidad sean presentadas en una estrecha asociación (por ejemplo World Bank, 1992; PNUD 1998).

No está muy claro sin embargo en qué medida las reformas institucionales propuestas mejoran las probabilidades de gobernabilidad del "Consenso de Washington". Buena parte de los desafíos recientes a la gobernabilidad de las sociedades en proceso de cambio provienen de la ausencia de resguardos o filtros de las economías individuales o regionales frente a la extraordinaria volatilidad alcanzada por la economía mundial, así como de la cesión, en beneficio de los actores del mercado, de instrumentos estratégicos de gestión pública. La afirmación de que tales filtros o regulaciones carecen ya de viabilidad a causa de la globalización del capitalismo es cuestionable sobre la base de una amplia experiencia.
El espacio abierto a las políticas nacionales y a algunos de sus instrumentos se ha reformulado en los años recientes, pero de ninguna manera ha desaparecido -por más que en las economías del mundo en desarrollo siempre fue más reducido que en los países industrializados. Puede incluso afirmarse que mucho del avance reciente de la globalización económica debe tanto o más al impulso dado a ella por determinadas políticas gubernamentales que a la dinámica espontánea del mercado (P. ej., Ibarra, 1996; Hirst \& Thompson, 1996; Strange, 1996; Doremus et al., 1998; Weiss, 1998; Veseth, 1998; Bouzas y Ffrench-Davis, 1998; Garrett, 1999). A esto se agrega el hecho, también conocido, del impacto de la liberalización de las economías latinoamericanas en el agravamiento de la fragmentación social y de las desigualdades sociales. Los sectores más acomodados se articulan rápidamente a las sociedades más avanzadas y adoptan sus patrones de consumo y sus perspectivas culturales - para lo cual siempre tuvieron una fuerte propensión- mientras aumenta la desintegración del resto de la población. La sociedad pierde cohesión; la profundización de las desigualdades sociales conspira contra el sentimiento de pertenencia a un todo compartido. La "comunidad imaginada" de la patria, la nación o incluso la clase, retrocede ante las lealtades particulares al grupo primario, a la corporación, a la firma de negocios, $\mathrm{o}$ a identificaciones contingentes

El desarrollo de mercados altamente concentrados estimula la privatización del Estado no sólo en lo que respecta a la provisión de bienes y servicios sino a su dimensión básica, ya señalada, de institucionalización de la estructura de poder y en su funcionamiento como administración pública. La coherencia básica que existe siempre entre estructuras socioeconómicas y regímenes políticos (un señalamiento que se remonta a Aristóteles) inclina a los gobiernos a tomar como referentes de su acción a los actores de mayor gravitación en el campo de la economía. Así como los movimientos de mujeres señalan la existencia de un "androcentrismo institucional" en algunas dimensiones del funcionamiento estatal, o los movimientos de identidad étnica identifican un "racismo institucional", es posible argumentar la existencia de preferencias institucionales que sesgan el funcionamiento del Estado hacia determinados actores del mundo de la economía. Se advierte en muchos casos que la ampliación de las capacidades de decisión política y de coerción legal para la reestructuración de la economía ha significado una clara instrumentalización del Estado en beneficio de los actores a cuyos objetivos o intereses se asigna un valor prioritario. La idea de una "autonomía relativa" del Estado respecto de los actores fundamentales de la sociedad resulta más apropiada a los escenarios institucionales del capitalismo administrado keynesiano o socialdemócrata (y sus variantes criollas), que a los del capitalismo avasallador de nuestros días (Vilas, 1997a). Consiguientemente,

20. Es llamativa la lentitud con la que el Banco Mundial reconoce este tipo de adaptaciones perversas cuando se llevan a cabo con fondos de la institución: cfr AFP (1999) y EFE (1999) sobre el caso del FONCODES en Perú. El problema venía siendo señalado por varias investigaciones independientes: por ejemplo HAYA DE LA TORRE (1995); MAUCERI (1995); VILAS (1998). Vid también IPS (1996). 
en los escenarios de astringencia fiscal que prevalecen en toda la región, la asignación de recursos públicos (financieros, materiales, legales o de otra índole) a los objetivos y actores priorizados puede implicar el abandono relativo del resto, o incluso el financiamiento de intereses particulares por el conjunto social. Pueden señalarse en este sentido, respectivamente, la modificación de las políticas sociales desde un enfoque de promoción a otro de contención, y la conversión de los pasivos de algunos grandes actores del sistema industrial o financiero privado en deuda pública (Vilas, 1997b; Moreno Pérez, 1998).

Es en este punto donde la variante pragmática del "más allá del Consenso de Wasbington" cobra relevancia. De acuerdo a ella, la promoción del mercado debe ir acompañada de una acción institucional encaminada a orientarlo y complementarlo, prevenir o compensar sus limitaciones y corregir sus imperfecciones. Se trata en el fondo de una propuesta de regular a los mercados y en tal sentido, más que avanzar "más allá del Consenso de Washington" plantea una reformulación del enfoque sustantivo del mismo en lo que toca a las relaciones entre el Estado y el mercado. La posición de Stiglitz respecto del "Consenso" es coherente con su trayectoria previa a su ingreso al Banco Mundial (Stiglitz, 1986) y se inscribe en la perspectiva de los estudios sobre el "gobierno de los mercados" (cfr. por ejemplo Wade, 1990). La diferencia principal con la propuesta de Burky y Perry reside no tanto en admitir la necesidad de cierta gestión estatal, sino en los objetivos hacia los cuales ella debería orientarse -y, en consecuencia, en el tipo de instrumentos que es necesario poner en movimiento.

Hablar de imperfecciones del mercado implica señalar la inexistencia o las limitaciones de las instituciones públicas que las prevengan y estimulen las reorientaciones necesarias. Lamentablemente, no se exploran todas las implicaciones de esta reformulación -en particular, el impacto que ella podría tener en la configuración de los apoyos políticos y sociales, internos y externos, que dieron viabilidad a las políticas del "Consenso". La hipótesis del enfoque pragmático parece asumir que el paso de un esquema de liberalización total a otro de regulación o complementación estatal es simplemente una cuestión de reorientación de los instrumentos de gestión o de diseño de nuevos instrumentos. La discusión precedente sugiere que un viraje de ese tipo siempre demanda una redefinición, parcial en el mejor de los casos, pero no por ello menos importante, de algunos de los acuerdos de poder entre los actores del mercado y la sociedad y conlleva, por lo tanto, modificaciones en sus articulaciones institucionales.

Algunos ejemplos sencillos ilustran la cuestión. La promoción de una política activa de formación y capacitación de recursos humanos, y la consiguiente asignación de recursos públicos, tiene sentido y es legítima como parte de determinados programas de desarrollo, y no de otros. Así, la experiencia latinoamericana de escuelas técnicas en el nivel secundario fue parte de un proyecto de industrialización que demandaba un cierto grado de planeación, por lo menos implícita, del mercado de trabajo y de las calificaciones laborales. A su turno ese estilo de industrialización se apoyó en un sistema de coaliciones y conflictos sociales e institucio- nales, y de articulación a los escenarios internacionales que, por conocido, no es necesario describir aquí. La sustitución de este proyecto por una estrategia de industria "de toque final" o de armado para la reexportación implica cambios de grandes proporciones en muchos aspectos, entre ellos la política de recursos humanos. El entrenamiento en el puesto de trabajo satisface ahora las demandas de calificación de las empresas de ensamble o de las plataformas de exportación; el concepto de planeación es reemplazado por criterios como "ajuste", "adecuación" o "corrección" de la oferta laboral a las cambiantes demandas de las firmas, que a su vez deben adaptarse rápidamente a los pedidos de los clientes -usualmente eslabones superiores en la cadena transnacional de producción/comercialización (Candia, 1999). Más aún, en este diseño la viabilidad, contenidos, alcances y recursos de una política de ciencia e innovación tecnológica, tienen un techo muy bajo.

Por su lado, una política de fomento de la competencia debe estar dispuesta a enfrentar las resistencias de las corporaciones o grupos económicos que se benefician de la apropiación de rentas de monopolio; sería una ingenuidad pensar que el éxito de tales políticas depende exclusivamente de la calidad técnica de su diseño. La acción reguladora del Estado deberá asentarse en una coalición social en la que la gravitación de los usuarios y consumidores actúe como contrapeso de la capacidad de presión de las firmas afectadas. En todo caso, la hipótesis misma de una regulación estatal del mercado, orientada a darle mayor competitividad, supone un tipo de capitalismo "relativamente organizado" que contrasta con lo que se observa en la actualidad.

El Estado puede colaborar con la reformulación de los acuerdos y las confrontaciones sociales, pero para ello hace falta mucho más que la profesionalidad, la sensibilidad o la rigidez de los funcionarios y sus asesores - cuya importancia no se subestima. No queda claro, en este sentido, quién habrá de ponerse el traje que la propuesta pragmática confecciona, además de los mismos funcionarios que vistieron las ropas del "Consenso". La cuestión de la agencia o, si se prefiere, del actor estratégico, no se presenta en el documento de Burky y Perry. Sus recomendaciones son, como ya se ha señalado, desarrollos de aspectos implícitos en la formulación original del "Consenso" y en este sentido se adaptan bien a las motivaciones y orientaciones de los actores que lo promueven y extraen beneficios de él. Pero Stiglitz plantea efectivamente "ir más allá" e incluso ir para otro lado, y no resulta evidente qué actores se harían cargo del viraje. Es conocida la resistencia de los grupos de mayor poder económico a recomendaciones de regulación como las que plantea el enfoque heterodoxo ${ }^{21}$. Tampoco parece sensato apostar sin más a la reconversión teórica o a la sensibilización de las burocracias internacionales; en las últimas dos décadas han mostrado una marcada ineptitud para extraer enseñanzas de los resultados de sus propias recomendaciones o para advertir

21. Recuérdense, por ejemplo, las reacciones del sector financiero de Argentina contra la iniciativa parlamentaria de regulación parcial de mercado de tarjetas de crédito: vid. La Nación (Buenos Aires) 26 de mayo

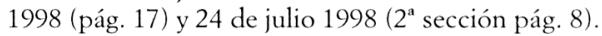


que el mundo suele ser más complejo que algunas simplificaciones teóricas.

Un sistema político democrático contribuye, en principio, a acotar las resistencias o bloqueos a la reorientación de los horizontes y las estrategias de desarrollo. Instituciones abiertas a la participación y representación amplias de la dinámica social ofrecen la posibilidad de que un mayor arco de demandas, intereses y objetivos sean tenidos en cuenta en los procesos de decisión, y obliga a los actores institucionales a responder públicamente por esas decisiones, incluso en cuestiones de administración cotidiana. Debe reconocerse empero, aunque resulte desagradable hacerlo, que en escenarios socioeconómicos como los predominantes en la mayor parte de América Latina, la democracia tiene límites. Pensar que en esos escenarios el voto individual es el único recurso de poder que los actores sociales movilizan en su relación con el Estado, implica incurrir en olvido de la vieja teoría pluralista de los grupos de presión, para no mencionar enfoques más radicales. En sociedades cruzadas por desigualdades muy profundas, el principio igualitario de "una persona, un voto" tiene una vigencia azarosa. Su valor cuantitativo coexiste con la evidencia de que la propiedad o el control de ciertos activos financieros, físicos, tecnológicos o simbólicos, pueden gravitar mucho más que el sufragio; la capacidad de los individuos para proponer o imponer decisiones institucionales se independiza del peso cuantitativo de su participación electoral individual. La elevada concentración de recursos de poder en ciertos actores sociales y del mercado, ya se ha visto, no es independiente del tipo de estrategia económica o de las políticas públicas inspiradas por los programas del "Consenso".

El modelo de la democracia de mercado implica costos de transacción entre política democrática y estímulos al mercado. La promoción acelerada de una economía de mercado implica priorizar institucionalmente los objetivos y perspectivas de las empresas que actúan en los sectores de mayor concentración, y de los grupos sociales respectivos. Es frecuente que el equilibrio entre la eficacia de las instituciones democráticas y la eficacia de determinadas fórmulas de política económica se tense y la balanza se incline hacia alguno de los extremos. El carácter ejemplar asignado por el Banco Mundial a algunas agencias administrativas "de elite" en la promoción de las reformas sugiere la opción del organismo por el segundo de los términos de la transacción. Esas agencias funcionaron como parte integral de regímenes autoritarios o abiertamente dictatoriales, a los que ni siquiera se ajusta la definición minimalista electoral de democracia (World Bank, 1997:83). Debe señalarse, en esta misma línea de análisis, que la democracia, que en el Informe de 1991 figuraba como un elemento integral de una estrategia de desarrollo "amistosa al mercado", desaparece como tal en documentos posteriores y, particularmente, en el Informe de 1997. El régimen de gobierno nunca figuró entre las consideraciones del Banco para decidir la eligibilidad de un país para sus líneas de financiamiento (Fishlow, 1994); es eso, quizás, lo que dio notoriedad a la referencia de 1991.

La misma ambigüedad rodea el auspicio del involucramiento de organismos no gubernamentales en ciertas dimensiones de la política social en el marco de los programas de ajuste y sus secuelas. La idea de recurrir a este tipo de organizaciones se remonta al enfoque de "poner primero a la gente" que estuvo presente en algunos programas de desarrollo rural del Banco Mundial en la década de 1980 (Cernea, 1985). Se reconocía bajo este nombre la importancia de las redes espontáneas de cooperación social para generar efectos compensatorios del impacto nocivo, en los grupos más vulnerables, de algunas dimensiones del ajuste estructural. En América Latina el enfoque se incorporó a la mayoría los programas de ajuste que se ejecutaron desde mediados de los años ochenta, y no se redujo al ámbito rural. El recurso a la capacidad de organización y de trabajo de un arco amplio de organizaciones sin fines de lucro fue presentado como una contribución a la democratización y a elevar la eficacia de los proyectos de inversión social, al ponerlos "cerca de la gente". Con el beneficio de la experiencia, es posible afirmar que el objetivo priorizado, no siempre explicitado, fue el ahorro de recursos financieros que significó el aporte de trabajo gratuito, o pobremente remunerado, de los grupos poblacionales involucrados en los proyectos -particularmente, trabajo de las mujeres. Además, el manejo centralizado de los recursos y del diseño de los proyectos favoreció la orientación de los fondos en función de la generación o retribución de lealtades políticas, más que de acuerdo al mapa de los grupos carenciados (Vilas, 1998: 27-53) 22. Es sabido asimismo que el enfoque participativo estimulado por el Banco Mundial dejó de lado las líneas troncales del ajuste económico, cuyo diseño siempre se mantuvo impermeable a las opiniones o reclamos de la misma sociedad civil de la que se esperaba que redujera el impacto social de aquél.

En muchos países de América Latina la reforma política del Estado es considerada de tanta o mayor prioridad que la reforma administrativa, e incluso una condición previa para ésta. Por reforma política se hace referencia a un conjunto de cuestiones que van desde los sistemas electorales y los criterios de representación irıstitucional, hasta las relaciones entre las funciones ejecutivas, legislativas y judiciales y sus respectivos aparatos institucionales, y entre las autoridades civiles y las fuerzas de defensa y seguridad. Para amplios grupos de población que se expresan en una variedad de asociaciones y modalidades -organismos no gubernamentales, organizaciones sindicales, partidos políticos, etcétera- una efectiva democratización de las instituciones y de las prácticas institucionales, formales y no formales, sigue siendo una asignatura pendiente de la reforma del Estado. México es un ejemplo pertinente, de ninguna manera único. En la percepción de muchos de sus actores sociales, cuestiones referidas a las dimensiones institucionales de la participación social, a la reforma del sistema electoral, a la representación política de ciertos actores sociales, a la responsabilidad de los funcionarios públicos, al acotamiento de las tradicionalmente muy amplias facultades presidenciales, tienen precedencia en las demandas y movilizaciones a favor de la reforma del Estado, por encima de la reforma

22. No pueden desconocerse sin embargo algunos resultados colaterales de estos experimentos de participación social: surgimiento o promoción de nuevos líderes de base, aprendizaje de las ventajas de la organización y la cooperación en proyectos colectivos, etcétera. 
administrativa. El objetivo de lar mayor eficacia a una red institucional considerada autoritaria y corrupta, ha sido reemplazado por el objetivo de ampliar la eficacia de la democracia como paso previo a un gerenciamiento institucional de más calidad y de plena transparencia (cfr. Alonso, 1996; Rodríguez Pratts, 1996).

Finalmente es llamativo que quede al margen de las propuestas de reforma institucional la cuestión de la calidad del gasto público y de los mecanismos de control, como también el mejoramiento de la calidad de la relación entre el Estado en tanto prestador de servicios administrativos, sociales o de otra índole, y el público destinatario de los mismos. En particular, es notable que los argumentos respecto de la responsabilidad de la corrupción en la generación de pobreza y en el retardo del crecimiento (World Bank, 1997; Burky y Perry, 1998) no estén acompañados por propuestas específicas de acotamiento del fenómeno. La tesis neoliberal circunscribe la corrupción al ámbito del Estado; atribuye el "riesgo moral" del mundo de los negocios -es decir, el involucramiento de empresas y empresarios en este tipo de arreglos informales con funcionarios o agencias estatales- a un exceso de energía empresarial que busca romper la inercia burocrática del Estado; define a la corrupción como una medida pragmática para eludir regulaciones inadecuadas o sacar el máximo de ventaja de las oportunidades que éstas ofrecen (De Soto, 1986; Escalante Gonzalbo, 1994). Congruente con este enfoque, el combate a la corrupción se reduce a propuestas de mayor liberalización de la economía, fortalecimiento de los tribunales y aceleración de los procedimientos judiciales. Se ha señalado ya la limitación del enfoque; la experiencia recogida en América Latina y en otras partes del mundo indica que las formas concretas de ejecución del ajuste han generado oportunidades de apropiación heterodoxa de recursos, que la iniciativa empresarial ha sabido aprovechar. El modo en que se ha llevado a cabo la desregulación y privatización del scctor financiero en varios países de la región está estrechamente vinculado a la expansión de cuestiones como el lavado de dinero proveniente del narcotráfico y de otras actividades económicas similarmente perniciosas. La falta de controles institucionales, o su ineficacia, parece tener responsabilidad en el auge creciente de estos rubros de la acumulación de capital ${ }^{23}$.

\section{CONCLUSIONES}

Las argumentaciones en torno a la necesidad, posibilidad o conveniencia de "ir más allá" de la formulación inicial del "Consenso de Washington" se centran en aspectos eminentemente instrumentales. La preocupación por estas cuestiones no es irrelevante; una política diseñada o ejecutada de manera chapucera puede conducir al fracaso a los objetivos más razonables. Pero la inhabilidad para advertir las proyecciones políticas y normativas de las recomendaciones instrumentales, o la renuencia a encararlas, reduce la solidez de los planteamientos y siembra dudas respecto de la utilidad del sendero propuesto para ir "más allá". La discusión de la sección anterior afirma, al contrario, que un tratamiento de los instrumentos sin una consideración a los objetivos de la acción estatal y sin referencia a las configuraciones de poder que les sirven de sustento, olvida la dimensión sustantiva de la problemática y contribuye a promover o a aceptar como ineludibles o inamovibles, objetivos contingentes a arreglos particulares de poder. Si por cuestiones de mandato la literatura producida por los organismos financieros multilaterales no está en condiciones de tomar en cuenta este tipo de asuntos, la respuesta a ellos deberá buscarse por otros derroteros: las limitaciones de la fuente no invalidan la relevancia de la problemática. Por tanto, lejos de concluir que una reorientación significativa de las políticas públicas actuales no es posible, la discusión aquí desarrollada sugiere, simplemente, que ella debe buscarse por otras vías.

Las propuestas del "post Consenso" aceptan en mayor o menor medida los arreglos de poder que el propio "Consenso" contribuyó a generar o consolidar; el "más allá" tiene en este sentido un horizonte cercano y avizorador. La variante que aquí se ha denominado pragmática cuestiona algunos de los ingredientes centrales de la fórmula original, pero comparte con la versión doctrinaria la omisión de una consideración de los objetivos que, más acá o más allá del "Consenso", orientan la estrategia de las reformas. En consecuencia, tampoco aporta sugerencias respecto de qué actores -aparte de algunos grupos de técnicos o funcionariosestarían dispuestos a acometerlas.

Considerada en sí misma, es decir con abstracción de las motivaciones que la impulsan y los objetivos que persigue, la intervención estatal no significa mucho, salvo posiblemente desde la perspectiva de la teoría neoclásica. El último siglo muestra un número amplio de intervenciones públicas en la estructura y funcionamiento de la economía, orientadas hacia una diversidad de objetivos y diseños macroeconómicos. Socialismo y capitalismo, tanto en sus vertientes democráticas como en las autoritarias, han recurrido a políticas activas, esquemas de planificación y amplia regulación de la actividad privada, en todos los casos con resultados muy variados. La especificidad de cada tipo de intervención provino sobre todo de la dinámica de conflictos y acuerdos entre actores sociales así como de los grandes objetivos que se trató de alcanzar y los problemas a los que se intentó dar respuesta. La definición de esos objetivos es siempre una actividad política, por más que por conveniencia o por error se la considere una cuestión técnica. Nuestro siglo conoció casos horriblemente perversos de gestión pública eficiente al servicio de objetivos deleznables: desde los campos nazis de exterminio hasta el prolijo registro de la desaparición de personas y el robo de recién nacidos del terrorismo de Estado, pasando por el body count de la guerra de Vietnam, que deberían ayudar a complementar el entusiasmo por los instrumentos con una acuciosa preocupación por los objetivos. Si la referencia resulta desagradable, la literatura latinoamericana brinda un ejemplo más ingenioso: el del capitán Pantaleón Pantoja, el personaje de Mario Vargas Llosa. Soldado disciplinado y patriota a carta cabal, el bueno

23. En 1998 el "Operativo Casablanca" del gobierno de Estados Unidos comprobó el activo involucramiento de parte del sistema financiero mexicano en el lavado de dinero proveniente del narcotráfico. Cfr. antecedentes de esta cuestión en ESTÉVEZ (1995 y 1996). 
de Pantaleón se convirtió en poco tiempo en el gerente público más eficiente y exitoso de lo que, de todos modos, nunca dejó de ser un lupanar de frontera.

Frente a las recomendaciones sobre el "más allá del Consenso de Washington" es dificil no recordar a la Alianza para el Progreso de la década de 1960. Después de haber colaborado durante décadas en la configuración de una estructura retardataria y autoritaria de poder en muchos de los países de la región, y de haber convertido a las élites latinoamericanas en pilares estratégicos de su hegemonía hemisférica, el gobierno estadounidense, gracias a la buena conciencia de algunos funcionarios de la presidencia de John F. Kennedy y a la necesidad de prevenir la reiteración de acontecimientos como la revolución en Cuba, trató de convencer a esas mismas élites que moderaran, de alguna manera, sus instintos más primordiales y aceptaran reformar sus propias bases de poder. El resultado es conocido. Las recomendaciones de reforma del "post-Consenso" son, por supuesto, mucho más modestas que las de la Alianza para el Progreso, y los desafíos de la desigualdad y el empobrecimiento suscitan menos alarma que los de los guerrilleros de la Sierra Maestra. De todos modos es incuestionable que el Banco y sus recomendaciones han sido parte del conjunto de actores y de ideas que contribuyeron a gestar la estructura de poder económico y en buena medida político, predominante hoy en la mayoría de los países de América Latina. Algunos de esos actores e ideas son preexistentes a la acción del Banco; pero el grado de preeminencia alcanzado por unos y otras encontró en las condiciones, recomendaciones y financiamiento del Banco -y de otros organismos multilaterales- un complemento estratégico. La evidencia disponible hasta el momento siembra dudas sobre las probabilidades de los proponentes del "post-Consenso" de conseguir resultados más auspiciosos que sus antecesores -aunque tampoco existen bases para descartarlas. La política, incluso la política reducida a administración, siempre es un juego de finales abiertos.

La preocupación por la eficacia, la eficiencia y la transparencia de las políticas públicas, debe decirse una vez más, no es irrelevante. Al contrario, importa mucho, por respeto a quienes de una u otra manera aportan los recursos con que se financia la gestión estatal, por una efectiva vigencia de una concepción más amplia de la democracia, por la funcionalidad de un buen gobierno a una política de desarrollo, por las fuertes restricciones fiscales que deben ser afrontadas, y porque siempre es mejor hacer bien las cosas que hacerlas mal. Sin embargo, una buena administración no mejora la calidad de los objetivos de las políticas a cuyo servicio se desenvuelve, del mismo modo que el tipo de vehículo hace el viaje más placentero o incómodo, veloz o lento, caro o económico, pero no modifica su dirección ni su destino -cuestiones éstas en las que el manejo del volante es insustituible.

\section{BIBLIOGRAFÍA}

AFP, Agencia France Press (1999): "Informa el Banco Mundial que Fujimori utilizó fondos para obras sociales con fines electoreros”. En Excélsior (Ciudad de México) 16 de octubre.
ALONSO, Jorge (1996): "La reforma democrática del Estado mexicano”. En Propuesta 3, agosto, 5-32.

Altimir, Oscar (1994): "Cambios en la desigualdad y la pobreza en América Latina”. En El Trimestre Económico 241, eneromarzo, 135-175.

Altimir, Oscar (1999): "Desigualdad, empleo y pobreza en América Latina: Efectos del ajuste y del cambio en el estilo de desarrollo". En Víctor E. Tokman y Guillermo O'Donnell (comps.), Pobreza y desigualdad en América Latina, Buenos Aires: Eudeba: 23-54

AspiAZU, Daniel (1998): "La elite empresaria y el ciclo económico. Centralización del capital, inserción estructural y beneficios extraordinarios". En H. Nochteff (ed.) La economía argentina a fin de siglo: fragmentación presente y desarrollo ausente. Buenos Aires: EUDEBA/FLACSO: 47-69.

BID, Banco Interamericano de Desarrollo (1998): América Latina frente a la desigualdad. Progreso Económico y Social de América Latina, Informe 1998-99. Washington D.C.: BID.

BANCO Mundial (1991): Informe sobre el desarrollo mundial 1991. La tarea acuciante del desarrollo. Washington D.C.: Banco Mundial.

BANCO Mundial (1995): Informe sobre el desarrollo mundial 1995. El mundo del trabajo en una economía integrada. Washington D.C.: Banco Mundial.

BERRY, Albert (1997): "The Income Distribution Threat in Latin America”. En Latin American Research Review, 32 (2) 3-40.

BOUZAS, Roberto y Ricardo FFRENCH-DAVIS (1998): "La globalización y la gobernabilidad de los países en desarrollo". En Revista de la CEPAL (octubre) 125-137.

Brennan, Geoffrey \& James M. BuCHANAN (1985): The Reason of Rules: Constitutional Political Economy. New York: Cambridge University Press.

Bresser Pereira, Carlos (1999a): "Ciudadanía y res publica: La emergencia de los derechos republicanos". En Nueva Sociedad 159 (enero-frebrero) 42-75

Bresser PEREIRA, Carlos (1999b): Reforma del Estado para la ciudadania. Buenos Aires: EUDEBA/CLAD.

BRowetT, John (1985): "The Newly Industrializing Countries and Radical Theories of Development". En World Development 13 (7) 789-803.

BROWN, Robert (1981): "Burocracia: La utilidad de un concepto". En E. Kamenka y M. Krygier (comps.), La burocracia. Trayectoria de un concepto. México: Fondo de Cultura Económica: 245-283.

BURKI, Shahid Javed \& Guillermo PERRY (eds.) (1998): Más allá del Consenso de Washington. La bora de la reforma institucional. Washington D.C.: Banco Mundial.

Callinicos, Alex (1999): Social Theory. A Historical Introduction. London: Polity Press.

Candia, José Miguel (1999): "Capacitación: ¿Vía de ingreso al trabajo o formas encubiertas de subsidiar el desempleo? Consideraciones sobre un debate inconcluso". En Tercera Edición 4 (diciembre) 13-20.

Cepal (1997): La brecha de la equidad. América Latina, el Caribe y la cumbre social. Santiago de Chile: CEPAL.

Cernea, Michael M. (ed.) (1985): Putting People First. Sociological Variables in Rural Development. New York: Oxford University Press.

CONCHEIRO BORQUEZ, Elvira (1996): El gran acuerdo. Gobierno y empresarios en la modernización salinista. México: Ediciones ERA.

Conaghan, Catherine, James Malloy \& Luis A. Abugattas (1990): "Business and the "Boys". The Politics of Neoliberalism in the Central Andes". En Latin American Research Review XXV (2) 3-30.

Corrigan, Philip \& Derek SAYER (1985): The Great Arch. English State Formation as Cultural Revolution. London: Basil Blackwell

De la PEÑA, Guillermo (1996): "Corrupción e informalidad". En Espiral, Estudios sobre Estado y Sociedad, III (7) 109-127. 
DE Soto, Hernando (1986): El otro sendero: La revolución informal. Lima: La Oveja Negra.

Doremus, Paul N., William Kelli R, Louis PaUly \& Simon Reich (1998): The Myth of the Global Corporation. Princeton: Princeton University Press.

EFE (1999): "Según informe del Banco Mundial, Fujimori hizo mal uso de fondos sociales". En El Mercurio (Santiago de Chile), 16 de octubre.

Escalante Gonzalbo, Fernando (1994): "Sobre el significado político de la corrupción”. En Política y Gobierno, I (1) 79-95.

Estevez, Dolia (1995): "Corupción y Narcolavado en las Privatizaciones Salinistas: FBI”. En El Financiero, (Ciudad de México), 9 de mayo.

Estevez, Dolia (1996): "La globalización económica, favorable al narco, alerta Paul Stares”. En El Financiero, (Ciudad de México), 20 de marzo.

Evans, Peter B., Dietrich Rueschmeyer \& Theda Skocpol (eds.) (1985): Bringing the State Back In, New York: Cambridge University Press.

FAZIO, Hugo (1997): Mapa actual de la extrema riqueza en Chile. Santiago: Universidad ARCIS

FISCHER, Stanley (1999): "Learning the Lessons of Financial Crises: The Roles of the Public and Private Sectors". Discurso en la reunión anual de la Market's Traders Association. Nueva York, 9 de diciembre.

FishLOW, Albert (1994): "Economic Development in the 1990s". En World Development, 22 (12) 1825-1832.

GaleANO, Eduardo (1976): La canción de nosotros. Buenos Aires: Ediciones de Crisis.

GARRETT, Geoffrey (1999): "Mercados globales y política nacional: ¿colisión inevitable o círculo virtuoso?”. En Desarrollo Económico, 152 (enero-marzo) 883-924.

GeORGE, Susan \& Fabrizio SABELli (1994): Faith and Credit. The World Bank Secular Empire. Boulder, Co.: Westview Press

GERSCHENKRON, Alexander (1962): El atraso económico en perspectiva histórica. Barcelona: Ariel.

GIDDENS, Anthony (1998): La tercera via. Barcelona: Taurus.

Gills, Barry \& George PhiLiP (1996): "Towards convergence in development policy? Challenging the 'Washington Consensus>". En Third World Quarterly, 17 (4) 585-591.

GueHenno, Juan-Marie (1995): El fin de la democracia. Barcelona: Paidos.

Haya DE LA Torre, Agustín (1995): "Las políticas sociales en Perú". En Carlos M. Vilas (coord.) Estado y políticas sociales después del ajuste. Caracas: Nueva Sociedad:87-100.

Heller, Hermann (1965): La soberanía. México: UNAM

Hintze, Otto (1931): "Las condiciones histórico-universales de la constitución representativa". En O. Hintze, Historia de las formas políticas. Madrid: Revista de Occidente, 1968:105-153.

Hirst, Paul \& Grahame ThOMPson (1996): Globalization in Question. London: Polity Press.

HuBER, Evelyne \& John D. STEPHENS (1986): Democratic Socialism in Jamaica. Houndmills: Macmillan.

IBARRA, David (1996): ¿Transición o crisis? Las contradicciones de la política económica y el bienestar social. México: Aguilar.

IPS (1996): "Menos de la tercera parte de los proyectos del Banco Mundial tienen éxito”. En La Jornada (Ciudad de México) 18 de diciembre.

JIMENEZ, Luis Felipe (1996): "La experiencia de ajuste durante la década de los ochenta en Latinoamérica, sus consecuencias distributivas y el diseño de políticas sociales". En CEPAL/ CLAD/SELA, Desarrollo con equidad. Caracas: Nueva Sociedad: $13-60$

JOHnSOn, Chalmers (1982): MITI and the Japanese Miracle. Stanford, Stanford U. Press.

Kitching, Gavin (1982): Development and Underdevelopment in Historical Perspective. London: Meuthen.

Kruijt, Dirk (1992): "Monopolios de filantropía: El caso de las llamadas "Organizaciones no Gubernamentales" en América Latina”. En Polémica 16 (2ª́poca) 41-47.
LACLAU, Ernesto (1991): "The imposibility of society", en Arthur y Marjorie Kroker (eds.) Ideology and Power in the Age of Lenin in Ruins. New York: St.Martin's Press: 24-27.

LAFAY, Jean-Dominique \& Jacques LACAILLON (1993): The Political Dimension of Economic Adjustment. Paris: OCDE.

LAKE, Anthony (1993): From Containment to Enlargement. Washington D.C.: Johns Hopkins University School of Advanced International Studies.

LEFTWICH, Adrian (1994): "Governance, the State, and the Politics of Development". En Development and Change, 25:363-386.

Liebich, André (1997): "The Communists Reincarnated. Their Return in Russia and Eastern Europe”. En World Affairs, 1 (1) 66-77.

LinZ, Juan \& Arturo Valenzuela (eds.) (1994): The Failure of Presidential Democracy. The Case of Latin America. Baltimore: Johns Hopkins University Press.

MarCH, James G. \& Johan P. OlsEN (1989): Rediscovering Institutions. The Organizational Basis of Politics. New York: The Free Press.

MarX, Karl (1859): "Crítica del programa del Gotha”, en K. Marx y F. Engels, En Obras escogidas. Moscú: Editorial Progreso 1971, tomo II.

Mauceri, Philip (1995): "State Reform, Coalitions, and the Neoliberal Autogolpe in Peru”. En Latin American Research Review 30 (1) 7-37.

MazLisH, Bruce (1991): "The Breakdown of Connections and Modern Development”, En World Development 19 (1) 31-44.

Moreno Perez, Juan (1998): "El problema del Fobaproa: Elementos para entenderlo y posibles alternativas para su solución”. En El Cotidiano. Revista de la realidad mexicana actual 92 (noviembre-diciembre) 52-83.

MORLEy, Samuel A. (1998): "La pobreza en tiempos de recuperación económica y reforma en América Latina: 1985-1995", en E. Ganuza, L. Taylor y S. Morley (eds.), Política macroeconómica y pobreza en América Latina y el Caribe. Madrid: MundiPrensa Libros:47-70.

MORRIS SuZUKI, Tessa (1998): Cultura, etnicidad y globalización. La experiencia japonesa. México: Siglo XXI/CEIICH-UNAM.

Mulgan, Geoff (1994): Politics in an Antipolitical Age. London: Polity Press.

Nelson, Joan (1989): "The Politics of Long-haul Economic Reform”. En J. Nelson (ed) Fragile Coalitions: The Politics of Economic Adjustment. New Brunswick NJ: Transaction Boks 1989: 3-25.

Nelson, Joan (1990) "The Politics of Economic Adjustment in Small Democracies: Costa Rica, the Dominican Republic and Jamaica", en J. Nelson (ed.) 169-214

Nelson, Joan (ed.) (1990): Economic Crisis and Policy Cboice. Princeton NJ: Princeton University Press.

NORTH, Douglass C. (1986): "The New Institutional Economics". En Journal of Institutional and Theoretical Economics 142: 230-237.

NoRTH, Douglass C. (1990): Institutions, Institutional Change, and Economic Performance. New York: Cambridge University Press.

O’Donnell, Guillermo (1995):"Delegative Democracy". En Journal of Democracy 5 (1) 65-69.

OECD (1990): Development Cooperation in the 1990s. Paris: OECD.

PAYER, Cheryl (1982a): Tanzania and the World Bank. Bergen: Christian Michelsen Institute.

PAYER, Cheryl (1982b): The World Bank. A Critical Analysis. New York: Monthly Review Press.

Pereira Almao, Valia (1997): "Personalización de la política y estabilidad democrática en América Latina”. En Boletín Electoral Latinoamericano XVIII (Julio-diciembre) 321-353.

PiOn-BERLin, David (1983): "Political Repression and Economic Doctrines: The Case of Argentina". En Comparative Political Studies 16 (1) April:37-66. 
PION-BERLIN, David (1989): The Ideology of State Terror. Economic Doctrine and Political Repression in Argentina and Perú. Boulder,Co.: Lynne Rienner.

Pipitone, Ugo (1994): La salida del atraso: Un estudio histórico comparativo. México: Fondo de Cultura Económica.

PNUD, Programa de las Naciones Unidas para el Desarrollo (1998): Gobernabilidad y desarrollo democrático en América Latina y el Caribe. Nueva York: PNUD.

PoGGI, Gianfranco (1990): The State. Its Nature, Development and Prospects. Stanford: Stanford University Press.

POLANYI, Karl (1957): La gran transformación. Los orígenes políticos y económicos de nuestro tiempo. México: Fondo de Cultura Económica 1992.

Pronovost, Gilles (1989): The Sociology of Time. Current Sociology 37 (3) Winter.

RAmOS TorRE, Ramón, comp. (1992): Tiempo y sociedad. Madrid: Centro de Investigaciones Sociológicas/Siglo XXI.

Rodriguez Pratts, Juan José (1996): “¿Por qué se reforma el Estado?”. En Propuesta 3, agosto 33-48.

Rudolph, Lloyd I. \& Susanne Hoeber Rudolph (1967): The Modernity of Tradition. Political Development in India. Chicago: The University of Chicago Press.

SAFA, Patricia (1993): "Una reflexión sobre individualismo y comu nidad a partir del concepto tiempo". En Iztapalapa 30:67-76.

SAMPAY, Arturo Enrique (1944): La filosofía del iluminismo y la Constitución argentina de 1853. Buenos Aires: Depalma.

SANTISO, Javier (1997): "Los relojes y las nubes: tiempo y democratización en América Latina y en Europa del Este”. En Política y Gobierno IV (1) 43-80.

SAYER, Derek (1991): Capitalism and Modernity. An excursus on Marx and Weber. London: Routledge.

SCHELling, Thomas C. (1973): Symposium: Time in Economic Life Quarterly Journal of Economics 87 (4) 627-675.

SHEAHAn, John (1989): Modelos de desarrollo en América Latina. México: Consejo Nacional para la Cultura y las Artes.

Stallings, Barbara (1990): "Politics and Economic Crisis; A Comparative Study of Chile, Perú, and Colombia", en Joan Nelson (ed). 113-168

STEPAN, Alfred \& SKACH, Cindy (1993): "Constitutional Frame works and Democratic Consolidation: Parliamentarism vs Presidentialism”. En World Politics 46 (October) 1-22.

STEPHEN, Lynn, (1991): "Culture as a Resource: Four Cases of SelfManaged Indigenous Craft Production in Latin America". En Economic Development and Cultural Change 40 (1) October 101-130;

Stiglitz, Joseph E. (1986): Economics of the Public Sector. New York: W.W. Norton.

Stiglitz, Joseph E. (1997): “Algunas enseñanzas del milagro del Este Asiático”. En Desarrollo Económico 147 (octubre-diciembre) 323-349.

STIGLITZ, Joseph E. (1998): "Más instrumentos y metas más amplias para el desarrollo. Hacia el consenso post-Washington”. En Desarrollo Económico 151 (Octubre-Diciembre) 691-722.

SToppino, Mario (1982): "Poder", en Norberto Bobbio y Nicola Matteucci, En Diccionario de Política, México: Siglo XXI, t. II: $1217-1227$

Strange, Susan (1996): The Retreat of the State. The Diffusion of Power in the World Economy. Cambridge: Cambridge University Press

TARRow, Sidney (1994): Powcr in Movement. Social Movements, Collective Action, and Politics. New York: Cambridge University Press

Tilly, Charles (1992): Coercion, Capital, and European States, AD 990-1992. London: Blackwell.

Toulmin, Stephen y June GOODFIELD (1968): El descubrimiento del tiempo. Buenos Aires: Paidos.

UNDP (1991): Human Development Report. New York: UNDP.

VEBLEN, Thorstein (1915): Imperial Germany and the Industrial Revolution. New York: Macmillan.
VESETH, Michael (1998): Selling Globalization. The Myth of the Global Economy. Boulder, Co.: Lynne Rienner.

VILAS, Carlos M. (1994a): "Economía, política y sociedad: Panorama después de la crisis”. En Realidad Económica 125 (julio-agosto) $4-26$.

VILAS, Carlos M. (1994b): "Entre la democracia y el neoliberalis mo: Los caudillos electorales de la postmodernidad”. En S. Dutrénit y L. Valdés (coords.) El fin de siglo y los partidos polí ticos en América Latina. México: Universidad Autónoma Metropolitana/Instituto Mora: 323-340.

VILAS, Carlos M. (1995): "Estado, actores y desarrollo: Los intercambios entre política y economía”. En Investigación Económica 212 (abril-junio) 177-195.

VILAS, Carlos M. (1996): "Prospects for Democratization in a PostRevolutionary Setting:Central America”. En Journal of Latin American Studies, 28 (May) 461-503

VILAS, Carlos M (1997a): "La reforma del Estado como cuestión política”. En Política y Cultura 8: 147, 185.

VILAS, Carlos M. (1997b): "De ambulancias, bomberos y policías: La política social del neoliberalismo (Notas para una perspectiva macro)". En Desarrollo Económico 144 (enero-marzo 1997) $931-952$

VILAS, Carlos M. (1998): América Latina: Experiencias comparadas de combate a la pobreza. México: Universidad Nacional Autónoma de México.

WADE, Robert (1990): Governing the Market. Princeton N.J. Princeton University Press.

WADE, Robert (1997): "Japón, el Banco Mundial y el arte del mantenimiento del paradigma: El milagro del Este asiático en perspectiva política". En Desarrollo Económico 147 (octubre diciembre) 351-387.

WEDER, Beatrice (1999): Model, Myth, or Miracle? Reassessing the Role of Governments in the East Asian Experience. Tokyo: United Nations University Press.

WEFFORT, Francisco (1992): Qual democracia?, São Paulo: Editora Schwarcz.

Weisberg, Herbert (ed.) (1986): Political Science: The Science of Politics. New York: Agathon Press.

WeIss, Linda (1998): The Myth of the Powerless State. Ithaca, N.Y.: Cornell University Press.

Williams, David \& Tom Young (1994): "Governance, the World Bank and Liberal Theory". En Political Studies XLII:84-100.

Williamson, John (1990): "What the Washington Consensus Means by Policy Reform", en J. Williamson (ed.) Latin America Adjustment: How Much bas Happened. Washington D.C.: The Institute for International Economics.

Williamson, John (1993): "Democracy and the «Washington Consensus»”. En World Development, 21 (8) 1329-1336.

Wolf, Eric (1966): "Kinship, Friendship, and Patron Client Rela tions in Complex Societies". En M. Barton (ed.) The Social Anthropology of Complex Societies. London: Tavistock Press: $1-22$.

WOLFE, Marshall (1990): "Las estructuras sociales y la democracia en los noventa”. En Revista de la CEPAL 49 (abril) 55-71.

World BANK (1989): Sub-Sabaran Africa: From Crisis to Sustainable Growth. Washington DC.: The World Bank.

WORLD BANK (1992): Governance and Development. Washington D.C.: The World Bank 1992

World Bank (1993a): The East Asian Miracle: Public Policy and Economic Growth. New York: Oxford University Press.

World BAnK (1993b): El Salvador: The Challenge of Poverty Alleviation. Washington D.C. (Report 12315-ES).

World BAnK (1994): Averting the Old Age Crisis. New York: Oxford University Press.

WorLd BANK (1997): World Development Report: The State in a Changing World. New York: Oxford University Press. 


\title{
PAPERS \\ Revista de sociologia \\ Universitat Autònoma de Barcelona
}

\begin{abstract}
SUMARI
Núm. 61, 2000

Reflexions sobre el canvi social, les desigualtats, la democràcia $\mathrm{i}$ altres qüestions teòriques
\end{abstract}

Clemente J. Navarro Yáñez, El sesgo participativo. Introducción a la teoría empírica de la democracia participativa.

Pedro SÁnchez Vera, Sociología de la vejez versus economía de la vejez.

J. Rubén Blanco, Juan Manuel Iranzo, Ambivalencia e incertidumbre en las relaciones entre ciencia y sociedad.

Daniel la ParRa Casado, Desigualdades de género durante la transición a la vida adulta. Estudio exploratorio.

J. Ángel Bergua, Movimientos sociales, diferencias culturales y paradojas. La negociación del riesgo en la regulación del río Ésera (Huesca).

Manuel Herrera Gómez, Representaciones de la sociedad: de la modernidad a la posmodernidad.

Eduardo Moyano, Procesos de cambio en la sociedad rural española. Pluralidad de intereses en una nueva estructura de oportunidades.

IÑAKE IRIARTE LÓPEZ, Sistemas autopoiéticos y juegos de lenguaje. El aire de familia entre Ludwig Wittgenstein y Niklas Luhmann.

\section{SUSCRIPCIONES}

Número suelto: 1.500 pta. anual (tres números: 60-62) 3.800 pta.; estudiante: 3.040 pta.; institucional: 4.300 pta.; extranjero: 46 US \$. Las solicitudes de suscripción han de dirigirse a: Servei de Publicacions de la Universitat Autònoma de Barcelona. Apartado postal 20. 08193 Bellaterra (Barcelona): Spain. El abono debe hacerse mediante transferencia bancaria a la cuenta 118-54 de la oficina 424 de "la Caixa" o con talón nominativo a Servei de Publicacions de la Universitat Autònoma de Barcelona (en este tipo de pago, sume al precio de la suscripción 250 pta. en concepto de gastos bancarios). Los envíos al extranjero tendrán un recargo de 3 US \$ para gastos de transporte. Para hacer efectiva la suscripción, ésta deberá ir acompañada del resguardo de la transferencia bancaria o del talón nominativo. 